\title{
Hypoxia Induced by Cobalt Chloride Triggers Autophagic Apoptosis of Human and Mouse Drug-Resistant Glioblastoma Cells through Targeting the PI3K-AKT-mTOR Signaling Pathway
}

\author{
Yuan-Wen Lee, ${ }^{1,2}$ Yih-Giun Cherng,,3 Shun-Tai Yang,, ${ }^{4,5}$ Shing-Hwa Liu, ${ }^{6}$ Ta-Liang Chen, ${ }^{2,7}$ \\ and Ruei-Ming Chen ${ }^{10}{ }^{1,5,7,8}$
}

${ }^{1}$ Anesthesiology and Health Policy Research Center; Department of Anesthesiology, Taipei Medical University Hospital, Taipei Medical University, Taipei 110, Taiwan

${ }^{2}$ Department of Anesthesiology, School of Medicine, College of Medicine, Taipei Medical University, Taipei 110, Taiwan

${ }^{3}$ Department of Anesthesiology, Shuang Ho Hospital, Taipei Medical University, New Taipei City 235, Taiwan

${ }^{4}$ Department of Neurosurgery, Shuang Ho Hospital, Taipei Medical University, New Taipei City 235, Taiwan

${ }^{5}$ Graduate Institute of Medical Sciences, College of Medicine, Taipei Medical University, Taipei 110, Taiwan

${ }^{6}$ Institute of Toxicology, College of Medicine, National Taiwan University, Taipei 100, Taiwan

${ }^{7}$ Cell Physiology and Molecular Image Research Center; Department of Anesthesiology, Wan Fang Hospital,

Taipei Medical University, Taipei 116, Taiwan

${ }^{8}$ TMU Research Center of Cancer Translational Medicine, Taipei 110, Taiwan

Correspondence should be addressed to Ruei-Ming Chen; rmchen@tmu.edu.tw

Received 30 January 2021; Revised 9 March 2021; Accepted 5 May 2021; Published 28 May 2021

Academic Editor: Miguel Sánchez Álvarez

Copyright (C) 2021 Yuan-Wen Lee et al. This is an open access article distributed under the Creative Commons Attribution License, which permits unrestricted use, distribution, and reproduction in any medium, provided the original work is properly cited.

Glioblastoma multiforme (GBM) is the most aggressive brain tumor. Drug resistance mainly drives GBM patients to poor prognoses because drug-resistant glioblastoma cells highly defend against apoptotic insults. This study was designed to evaluate the effects of cobalt chloride $\left(\mathrm{CoCl}_{2}\right)$ on hypoxic stress, autophagy, and resulting apoptosis of human and mouse drug-resistant glioblastoma cells. Treatment of drug-resistant glioblastoma cells with $\mathrm{CoCl}_{2}$ increased levels of hypoxia-inducible factor- (HIF-) $1 \alpha$ and triggered hypoxic stress. In parallel, the $\mathrm{CoCl}_{2}$-induced hypoxia decreased mitochondrial ATP synthesis, cell proliferation, and survival in chemoresistant glioblastoma cells. Interestingly, $\mathrm{CoCl}_{2}$ elevated the ratio of light chain (LC)3-II over LC3-I in TMZresistant glioblastoma cells and subsequently induced cell autophagy. Analyses by loss- and gain-of-function strategies further confirmed the effects of the $\mathrm{CoCl}_{2}$-induced hypoxia on autophagy of drug-resistant glioblastoma cells. Furthermore, knocking down HIF- $1 \alpha$ concurrently lessened $\mathrm{CoCl}_{2}$-induced cell autophagy. As to the mechanisms, the $\mathrm{CoCl}_{2}$-induced hypoxia decreased levels of phosphoinositide 3-kinase (PI3K) and successive phosphorylations of AKT and mammalian target of rapamycin (mTOR) in TMZ-resistant glioblastoma cells. Interestingly, long-term exposure of human chemoresistant glioblastoma cells to $\mathrm{CoCl}_{2}$ sequentially triggered activation of caspases-3 and -6, DNA fragmentation, and cell apoptosis. However, pretreatment with 3methyladenine, an inhibitor of autophagy, significantly attenuated the $\mathrm{CoCl}_{2}$-induced autophagy and subsequent apoptotic insults. Taken together, this study showed that long-term treatment with $\mathrm{CoCl}_{2}$ can induce hypoxia and subsequent autophagic apoptosis of drug-resistant glioblastoma cells via targeting the PI3K-AKT-mTOR pathway. Thus, combined with traditional prescriptions, $\mathrm{CoCl}_{2}$-induced autophagic apoptosis can be clinically applied as a de novo strategy for therapy of drug-resistant GBM patients.

\section{Introduction}

Glioblastoma multiforme (GBM) is the most malignant brain tumor. In the clinic, GBM patients are regularly cured with standard surgical resection and successive concurrent chemoradiotherapy [1]. Temozolomide (TMZ) is the first-line chemotherapeutic drug for GBM [2]. Unfortunately, more than $50 \%$ of GBM patients will ultimately exhibit drug 
resistance and recurrence [3]. Because GBM develops in the brain, this cerebral location limits neurosurgeons' performance of completely removing tumors [4]. Moreover, glioblastoma cells possess unique features of rapid proliferation, migration, and invasion [5]. Following surgery, residual glioblastoma cells existing on the periphery of a brain tumor can speedily proliferate and invade other areas to recur as moreaggressive brain tumors [4]. As a result, GBM patients usually have very poor prognoses. Even if patients are energetically cured, their average survival is only 12 18 months [6]. Until now, chemoresistance is still a key challenge for therapy of glioblastomas. Therefore, establishing de novo strategies to overwhelm drug tolerance by GBM is an emergent and necessary issue.

Mammalian cells require an adequate supply of oxygen for energy production in order to support cell activities and functions. Hypoxia is a condition in which there is an insufficient oxygen source in a region of the body [7]. Being related to physiological and pathological situations, hypoxia is highly associated with human health and diseases, especially in the brain $[8,9]$. Throughout its entire lifespan, the human brain is often threatened by cerebral hypoxia [10]. For example, prenatal hypoxia that occurs in a key stage of brain formation may cause morphological variations in brain structures that are involved in learning and memory and ultimately affect development of cognitive functions. In ischemic brain diseases, hypoxia can directly disrupt the integrity of the blood-brain barrier (BBB), thus leading to vasogenic edema, brain swelling, and neuronal injury [11]. Moreover, cerebral hypoxia can also be induced by certain diseases, such as asthma, that interfere with breathing and blood oxygenation [12]. More attractively, hypoxia is also detected in solid cancers, particularly in brain tumors [13]. Hypoxic conditions may induce insults to glioblastoma cells. Otherwise, in response to hypoxic stress, glioblastoma cells can produce and excrete vascular endothelial growth factor (VEGF) to stimulate neovascularization from preexisting blood vessels [14]. In response to hypoxic stimuli, hypoxia-induced factor(HIF-) $1 \alpha$, a subunit of heterodimeric HIF-1, can be significantly upregulated and then functions as a representative transcription factor to regulate downstream gene expressions [9, 15]. A number of studies disclosed the complexity and importance of the HIF-1 $\alpha$ signaling pathway in hypoxia [16]. Accordingly, HIF- $1 \alpha$ and its downstream targets are emerging as novel therapeutic options for treating brain tumors.

Autophagy, a process of self-degradation and catabolism, is generally considered to be a survival mechanism in response to nutrient insufficiency-induced stress [17]. In addition, autophagy participates in preventing certain diseases, such as cancer, neuronal disorders, cardiomyopathy, diabetes, liver disease, autoimmune diseases, and infections, by engulfing damaged organelles and intracellular ribosomes and protein aggregates into double-membraned autophagosomes. Hypoxia can induce cell autophagy [18]. In the hypoxic tissue microenvironment, adenosine monophosphate- (AMP-) activated protein kinase (AMPK) is activated due to an increase in the ratio of intracellular AMP and adenosine triphosphate (ATP) [19]. Subsequently, activated AMPK can trigger cell autophagy through directly inducing autophagy-associated light chain 3 (LC3) and indirectly suppressing activity of the mammalian target of rapamycin (mTOR) $[13,20]$. When oxygen deprivation occurs in the tissue microenvironment, HIF- $1 \alpha$ is proximately induced and then activated in response to hypoxic stress [21]. HIF- $1 \alpha$ can induce cell autophagy via inducing BNIP3 and LC3 expressions [22]. Traditionally, hypoxia-induced autophagy is thought to promote tumor resistance [13]. In addition to autophagy, hypoxic conditions can induce cell apoptosis and necrosis in follicles of mammalian ovaries [18]. Our previous study showed that honokiol, an anticancer drug, induces autophagic insults to neuroblastoma cells via activation of the phosphoinositide 3-kinase- (PI3K-) AKT-mTOR and endoplasmic reticular (ER) stress/extracellular signalregulated kinase (ERK)1/2 signaling pathways [23]. Moreover, a longer period of treatment with honokiol led to autophagy and the death of glioblastoma cells [24]. Our previous study also demonstrated that cobalt chloride $\left(\mathrm{CoCl}_{2}\right)$, an inducer of HIF- $1 \alpha$, can be used as a chemical hypoxia model to induce autophagic death of human glioblastoma cells via a p53-dependent mechanism [25]. More than 50\% of GBM patients ultimately exhibit chemoresistance, and drug-resistant glioblastoma cells highly defend against apoptotic insults [1]. In this study, we successfully isolated human and mouse TMZ-resistant glioblastoma cells as our experimental models to investigate whether or not a prolonged administration of hypoxia could induce autophagic killing of drug-resistant glioblastoma cells and the possible action mechanisms, focusing on the PI3K-AKT-mTOR signaling pathway.

\section{Materials and Methods}

2.1. Selection and Culturing of Human and Mouse DrugResistant Glioblastoma Cells. TMZ-sensitive human U87 MG and mouse GL261 cells were used for selection of drug-resistant U87 MG-R and GL261-R glioblastoma cells as described previously [26]. In brief, U87 MG and GL261 cells were seeded in 12-well tissue culture plates at a density of $10^{5}$ cells per well and maintained in Dulbecco's modified Eagle's medium (DMEM; Gibco-BRL Life Technologies, Grand Island, NY, USA) with 10\% fetal bovine serum, $100 \mu \mathrm{g} / \mathrm{ml}$ streptomycin sulfate, and $100 \mathrm{U} / \mathrm{ml}$ penicillin and cultured in a humidified incubator with $5 \% \mathrm{CO}_{2}$ at $37^{\circ} \mathrm{C}$. Glioblastoma cells were treated with $50 \mu \mathrm{M}$ TMZ for 2 days. Later, human U87 MG and mouse GL261 cells were trypsinized and diluted 0.2 1.0-fold. Diluted cells were cultured in DMEM with $100 \mu \mathrm{M}$ TMZ. Surviving cell colonies were dissociated with trypsin and further grown in culture medium containing $100 \mu \mathrm{M}$ TMZ. After sequential selection of drug-resistant glioblastoma cell colonies, TMZ-tolerant U87 MG-R and GL261-R cells were successfully selected. Human normal astrocytes (HA-h) purchased from ScienCell Research Laboratories (Carlsbad, CA, USA) were cultured in astrocyte medium (ScienCell Research Laboratories).

2.2. Creation of Hypoxic Conditions and Drug Treatment. Hypoxic conditions in drug-resistant U87 MG-R and GL261-R glioblastoma cells were created by inducing HIF- $1 \alpha$ 
expression following treatment with $\mathrm{CoCl}_{2}$ as described previously [25]. $\mathrm{CoCl}_{2}$, bought from Sigma (St. Louis, MO, USA), was freshly dissolved in phosphate-buffered saline (PBS), containing $\mathrm{NaCl}(0.14 \mathrm{M}), \mathrm{KCl}(2.6 \mathrm{mM}), \mathrm{Na}_{2} \mathrm{HPO}_{4}(8 \mathrm{mM})$, and $\mathrm{KH}_{2} \mathrm{PO}_{4}$ (1.5 mM). TMZ-resistant U87 MG-R and GL261-R glioblastoma cells were exposed to $100 \mu \mathrm{M} \mathrm{CoCl} 2$ for 6,12 , and $24 \mathrm{~h}$. Levels of HIF- $1 \alpha$ were measured in order to confirm hypoxic conditions in drug-resistant glioblastoma cells. Control cells received PBS only.

2.3. Analyses of Cell Morphology and Survival. Morphologies and survival of human and mouse drug-sensitive and -resistant glioblastoma cells were analyzed according to a previously described method [27]. Drug-resistant glioblastoma cells $\left(10^{4}\right.$ cells/well) were seeded in 12-well tissue culture plates overnight. After drug treatment, cell morphologies were observed and photographed using an inverted light microscope (Nikon, Tokyo, Japan). Then, the cells were trypsinized with $0.1 \%$ trypsin-EDTA. After centrifugation, glioblastoma cells were suspended in PBS buffer and stained with a trypan blue dye. Fractions of living cells with white signals were visualized and counted with a light microscope (Nikon).

2.4. Examination of Cell Proliferation. Proliferation of human drug-resistant glioblastoma cells was assayed by analyzing the incorporation of bromodeoxyuridine (BrdU) into genomic DNA as described previously [28]. Glioblastoma cells at $3 \times 10^{3}$ cells/well were seeded in a 96-well cell culture plate. Following $\mathrm{CoCl}_{2}$ treatment, replicating glioblastoma cells were reacted with $10 \mathrm{mM}$ BrdU for a further $2 \mathrm{~h}$. Then, human drug-tolerant glioblastoma cells were fixed with $4 \%$ paraformaldehyde. A cell proliferation enzyme-linked immunosorbent assay (ELISA) kit purchased from Roche (Mannheim, Germany) was used in this study to measure amounts of BrdU incorporated into genomic DNA of glioblastoma cells. Signals were read using a microplate photometer (Thermo Fisher Scientific, Tewksbury, MA, USA) and statistically analyzed.

2.5. Assay of Mitochondrial $N A D(P) H$ Oxidoreductase Activity. A colorimetric method was carried out to examine activities of mitochondrial $\mathrm{NAD}(\mathrm{P}) \mathrm{H}$-dependent oxidoreductase enzymes in human drug-resistant glioblastoma cells as described previously [29]. Briefly, human drug-resistant glioblastoma cells were seeded in 96-well cell culture plates at a density of $10^{4}$ cells/well for $12 \mathrm{~h}$. After exposure to $\mathrm{CoCl}_{2}$, TMZ-tolerant glioblastoma cells were cultured with fresh DMEM containing $0.5 \mathrm{mg} / \mathrm{ml} \mathrm{3-(4,5-dimethylthiazol-2-yl)-}$ 2,5-diphenyltetrazolium bromide for a further $3 \mathrm{~h}$. The formazan products, metabolized by mitochondrial $\mathrm{NAD}(\mathrm{P}) \mathrm{H}$ oxidoreductases, were then dissolved in DMSO. Dark-brown signals were spectrophotometrically measured at $550 \mathrm{~nm}$ using a spectrophotometer (BioTek, Winooski, VT, USA).

2.6. Levels of Cellular ATP. A bioluminescence assay was conducted to measure levels of cellular ATP in human TMZresistant glioblastoma cells following the protocol of an ATP determination kit (Molecular Probes, Eugene, OR, USA) as described previously [30]. This assay was based on the luciferase requirement for ATP to produce $560 \mathrm{~nm}$ illu- minant signals. A multilabel counter, obtained from BMG Labtech (Offenburg, Germany), was used to measure intensities of the illuminant light. Values were analyzed using the Gen5 software (vers. 3.03, BMG Labtech).

2.7. Quantification of Autophagic Cells. Proportions of autophagic cells were quantified by assessing acidic vesicular organelles in drug-resistant glioblastoma cells as described previously [23]. Following exposure to $\mathrm{CoCl}_{2}$, human and mouse drug-resistant glioblastoma cells at a density of $10^{5}$ cells/well were treated with $1 \mu \mathrm{g} / \mathrm{ml}$ acridine orange for $20 \mathrm{~min}$. After that, these TMZ-tolerant glioblastoma cells were harvested in DMEM without phenol red. A flow cytometer (Beckman Coulter, Fullerton, CA, USA) was used in this study to quantify levels of acridine orange with green and red fluorescence in glioblastoma cells. Intensities of fluorescent signals were analyzed using software from Beckman Coulter. 3-Methyladenine (3-MA), an inhibitor of autophagy, and rapamycin, an inducer of autophagy, were purchased from Sigma. 3-MA and rapamycin were dissolved in dimethyl sulfoxide (DMSO). After pretreatment with $1 \mathrm{mM}$ 3-MA or $0.5 \mu \mathrm{M}$ rapamycin for $1 \mathrm{~h}, \mathrm{U} 87 \mathrm{MG}-\mathrm{R}$ and GL261$\mathrm{R}$ glioblastoma cells were then exposed to $\mathrm{CoCl}_{2}$. Control cells received DMSO only.

2.8. Activities of Caspases-3 and -6. A fluorometric substrate assay was conducted to quantify activation of caspases- 3 and -6 in human and mouse TMZ-resistant glioblastoma cells as described previously [31]. In brief, after $\mathrm{CoCl}_{2}$ treatment, human and mouse drug-resistant glioblastoma cells were lysed using a buffer containing Nonidet P-40 (1\%), $\mathrm{NaCl}(200 \mathrm{mM})$, Tris/HCl (pH 7.4, $20 \mathrm{mM})$, leupeptin $(10 \mathrm{mg} / \mathrm{ml})$, aprotinin $(0.27 \mathrm{U} / \mathrm{ml})$, and phenylmethylsulfonyl fluoride (PMSF, $100 \mathrm{mM}$ ). Cell extracts were incubated with a specific fluorogenic peptide substrate at $50 \mathrm{mM}$ in a cell-free system buffer containing HEPES (pH 7.4, $10 \mathrm{mM}$ ), mannitol (220 mM), sucrose (68 mM), $\mathrm{NaCl}(2 \mathrm{mM}), \mathrm{KH}_{2} \mathrm{PO}_{4}$ $(2.5 \mathrm{mM})$, ethylene glycol tetraacetic acid $(0.5 \mathrm{mM}), \mathrm{MgCl}_{2}$ $(2 \mathrm{mM})$, pyruvate $(5 \mathrm{mM}), \mathrm{PMSF}(0.1 \mathrm{mM})$, and dithiothreitol $(1 \mathrm{mM})$. DEVD and VEID are specific peptide substrates for, respectively, detecting caspase- 3 and -6 enzyme activities. For fluorescent detection, the DEVD and VEID substrates were conjugated with 7-amino-4-(trifluoromethyl)coumarin. A spectrometer (BMG Labtech) was used to measure intensities of the fluorescent products metabolized by caspases- 3 and -6. Fluorescent values were examined using software from BMG Labtech and statistically analyzed.

2.9. Quantification of DNA Fragmentation. DNA fragmentation in human and mouse drug-sensitive and -resistant glioblastoma cells was quantified using a cellular ELISA kit (Boehringer Mannheim, Indianapolis, IN, USA) as described previously [32]. In brief, TMZ-tolerant glioblastoma cells were subcultured in 24-well tissue culture plates at a density of $2 \times 10^{5}$ cells/well and labeled with BrdU for $12 \mathrm{~h}$. Human and mouse glioblastoma cells were then harvested and suspended in culture medium. The cell suspension $(100 \mu \mathrm{l}$ per well) was added to 96-well tissue culture plates. Drugsensitive and -resistant glioblastoma cells were cultured 
under hypoxic conditions for various time periods in a humidified incubator with $5 \% \mathrm{CO}_{2}$ at $37^{\circ} \mathrm{C}$. Levels of BrdUlabeled DNA in the cytoplasm were measured with a microplate photometer (BMG Labtech) at $450 \mathrm{~nm}$. The data of DNA fragmentation were then analyzed using software from BMG Labtech.

2.10. Assay of Apoptotic Cells. Proportions of drug-sensitive and -resistant glioblastoma cells under apoptotic insults were examined according to a previously described method [33]. After drug administration, glioblastoma cells were harvested and fixed in cold $80 \%$ ethanol. Following centrifugation and washing, fixed glioblastoma cells were stained with propidium iodide. A flow cytometer (Beckman Coulter) was used to measure fluorescent signals with a $560 \mathrm{~nm}$ dichroic mirror and a $600 \mathrm{~nm}$ bandpass filter. Intensities of these fluorescent signals in glioblastoma cells were quantified with software from Beckman Coulter.

2.11. Immunoblot Analysis. Immunoblot analyses were carried out to immunodetect levels of HIF-1 $\alpha$, LC3-I, LC3-II, PI3K, phosphorylated- (p-) and nonphosphorylated AKT and mTOR, vimentin, and $\beta$-actin in drug-resistant glioblastoma cells as described previously [34]. After exposure to hypoxia, lysates of drug-resistant glioblastoma cells were prepared in ice-cold radioimmunoprecipitation assay (RIPA) buffer, containing Tris- $\mathrm{HCl}$ (pH 7.2, $25 \mathrm{mM}$ ), Triton X-100 (1\%), sodium dodecylsulfate (SDS, $0.1 \%)$, EDTA (1 mM), and $\mathrm{NaCl}(0.15 \mathrm{M})$. A mixture of proteinase inhibitors, viz., leupeptin $(5 \mu \mathrm{g} / \mathrm{ml})$, sodium orthovanadate $(1 \mathrm{mM})$, and PMSF ( $1 \mathrm{mM}$ ), was added to ice-cold RIPA buffer to prevent protein degradation. A bicinchonic acid protein assay kit purchased from Pierce (Rockford, IL, USA) was used to quantify protein concentrations. Cell lysates were loaded into SDS-polyacrylamide gel and electrophoretically separated. Then, the proteins were electrophoretically transferred to nitrocellulose membranes. Fiver percentage of on-fat milk was used to block the membranes at $37^{\circ} \mathrm{C}$ for $1 \mathrm{~h}$. HIF- $1 \alpha$ was immunodetected using a mouse monoclonal antibody (mAb) against human HIF-1 $\alpha$ (Cell Signaling Technology, Danvers, MA, USA). LC3-I, LC3-II, PI3K, AKT, p-AKT, $\mathrm{mTOR}$, and $\mathrm{p}-\mathrm{mTOR}$ were recognized using mAbs or polyclonal antibodies (pAbs) purchased from Cell Signaling Technology. Cellular vimentin and $\beta$-actin proteins were immunodetected using mouse mAbs against human vimentin and mouse $\beta$-actin (Sigma), respectively. These immunoreactive protein bands were quantified with a digital imaging system (Syngene, Cambridge, UK) as described previously [35]. Intensities of these protein bands were analyzed using $\beta$-actin as the internal loading control.

2.12. HIF-1 $\alpha$-Knockdown. An RNA interference (RNAi) technique was applied in this study to knock down translation of HIF- $1 \alpha$ as described previously [36]. HIF- $1 \alpha$ small interfering (si) RNA (sc-35561), scrambled siRNA (sc37007), and siRNA transfection medium (sc-36868) were purchased from Santa Cruz Biotechnology (Santa Cruz, CA, USA). At first, human TMZ-resistant glioblastoma cells were cultured in antibiotic-free DMEM and maintained in a humidified incubator with an atmosphere of $5 \% \mathrm{CO}_{2}$ at $37^{\circ} \mathrm{C}$ for $24 \mathrm{~h}$. After that, the HIF- $1 \alpha$ siRNAs were diluted in siRNA transfection medium, and a HIF- $1 \alpha$ siRNA duplex solution was added to the cells for transfection for $48 \mathrm{~h}$. After replacing the old medium with normal DMEM, human U87 MG-R cells were exposed to $\mathrm{CoCl}_{2}$. Scrambled siRNA was applied as a negative control.

2.13. Statistical Analysis. Each value represses the mean \pm standard deviation (SD) for at least three independent determinations. Statistical analyses were carried out using a twoway analysis of variance (ANOVA) and a post hoc Duncan's multiple-range test. Statistical differences were considered significant at $p<0.05$.

\section{Results}

3.1. Selection and Preparation of Human and Mouse DrugResistant Glioblastoma Cells. Human and mouse glioblastoma cells that were resistant to TMZ treatment were prepared from their respective drug-sensitive brain tumor cells (Figure 1). No difference in morphologies of human drugsensitive U87 MG and -resistant U87 MG-R cells was observed (Figure 1(a)). Exposure to TMZ at 25, 50, 75, and $100 \mu \mathrm{M}$ for $72 \mathrm{~h}$ caused significant $19 \%, 30 \%, 38 \%$, and $51 \%$ decreases in survival of human U87 MG cells, respectively (Figure 1(b)). In contrast, treatment of human U87 MG-R glioblastoma cells with various concentrations of TMZ for $72 \mathrm{~h}$ did not change cell survival. Furthermore, exposure of U87 MG cells to $100 \mu \mathrm{M}$ TMZ for $72 \mathrm{~h}$ led to a significant 98\% augmentation in DNA fragmentation (Figure 1(c)). The DNA integrity of U87 MG-R glioblastoma cells was not influenced by TMZ. Administration of TMZ at $100 \mu \mathrm{M}$ for $72 \mathrm{~h}$ led to a significant $48 \%$ elevation in apoptosis of human U87 MG cells (Figure 1(d)). At the same treated condition, TMZ did not trigger apoptosis of human U87 MG-R cells. Moreover, TMZ induced DNA fragmentation and cell apoptosis in drug-sensitive GL261 glioblastoma cells by $64 \%$ and $41 \%$, respectively (Figures $1(\mathrm{e})$ and $1(\mathrm{f})$ ). In comparison, treatment of mouse drug-resistant GL261-R glioblastoma cells with $100 \mu \mathrm{M}$ TMZ for $72 \mathrm{~h}$ did not trigger DNA fragmentation or cell apoptosis.

3.2. Exposure of Human and Mouse TMZ-Resistant Glioblastoma Cells to $\mathrm{CoCl}_{2}$ Increased Levels of HIF-1 $\alpha$ and Led to Cell Death. Effects of $\mathrm{CoCl}_{2}$ on hypoxic insults to human TMZ-tolerant U87 MG-R cells were investigated (Figure 2). Treatment with $100 \mu \mathrm{M} \mathrm{CoCl}_{2}$ for $6 \mathrm{~h}$ augmented levels of HIF- $1 \alpha$ in U87 MG-R cells (Figure 2(a), top panel, lane 1). At 12 and $24 \mathrm{~h}$ after hypoxic treatment, HIF- $1 \alpha$ in U87 MG-R cells were time-dependently elevated (lanes 3 and 4$). \beta$-Actin was measured as the internal loading standard (bottom panel). The protein band intensities were statistically analyzed (Figure 2(b)). Exposure to $\mathrm{CoCl}_{2}$ for 6 , 12 , and $24 \mathrm{~h}$ caused respective 2.4-, 2.9-, and 3.8-fold increases in levels of HIF-1 $\alpha$ in human U87 MG-R glioblastoma cells. In comparison, exposure of human U87 MG-R cells to $\mathrm{CoCl}_{2}$ for 6,12 , and $24 \mathrm{~h}$ did not change levels of vimentin (Fig. S1). Compared to the untreated group, 

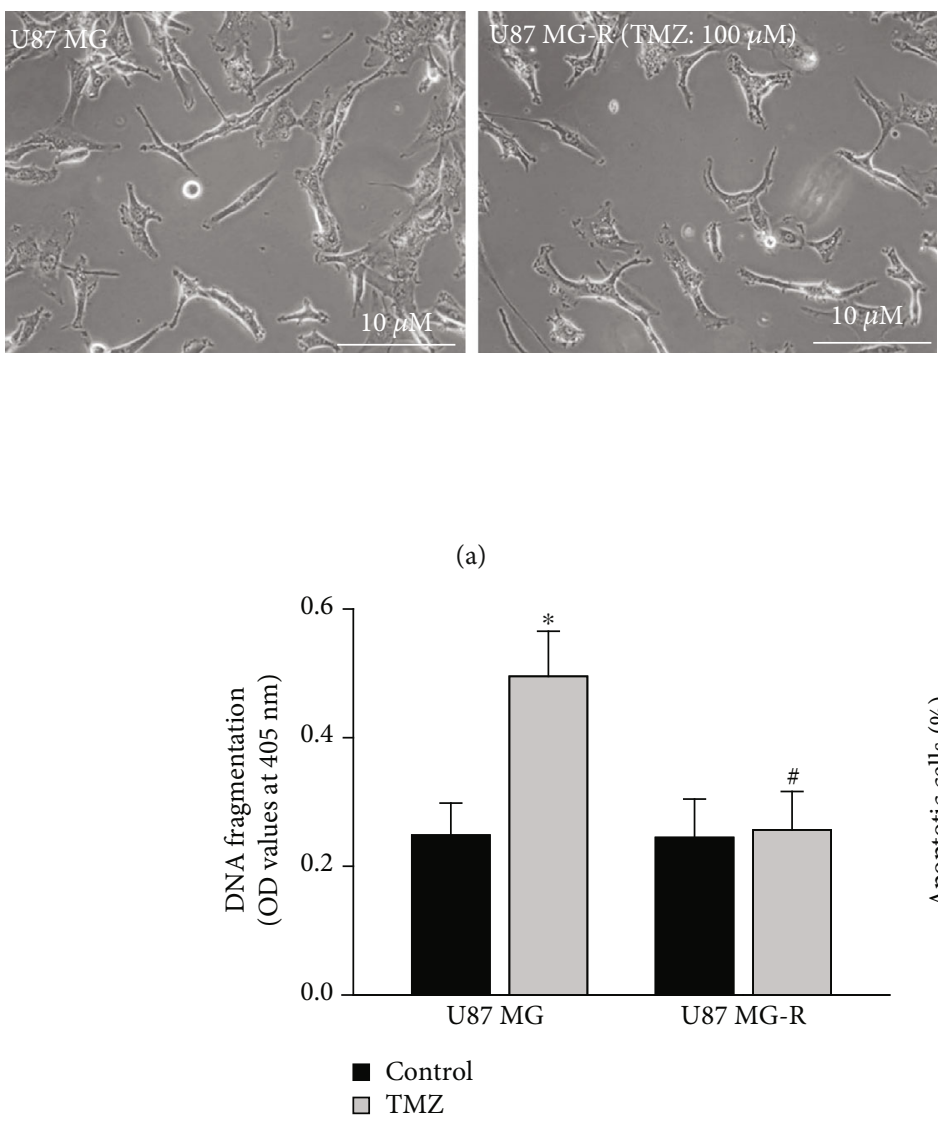

(c)

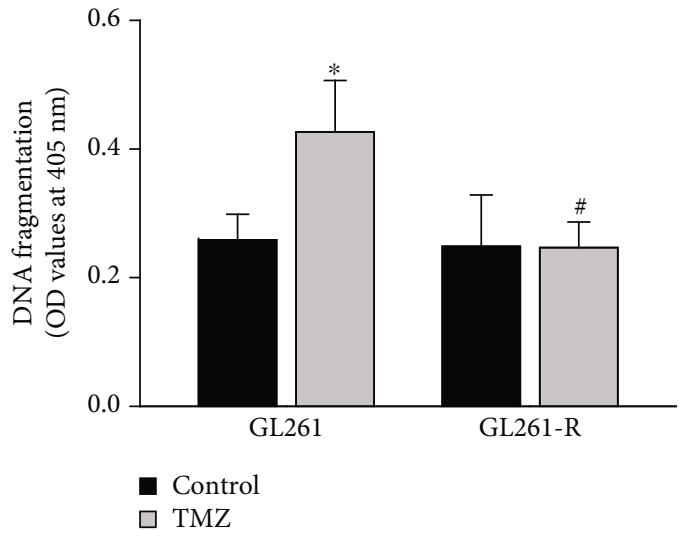

(e)

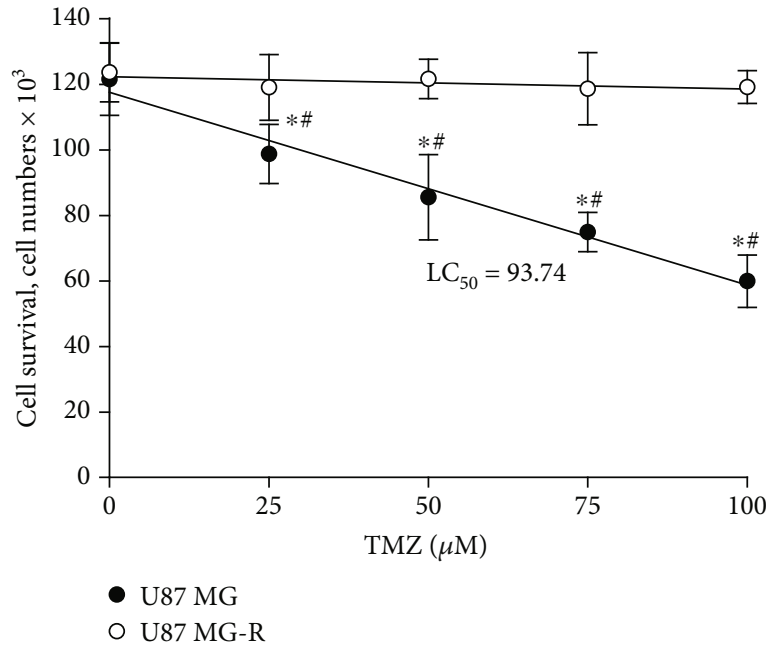

(b)

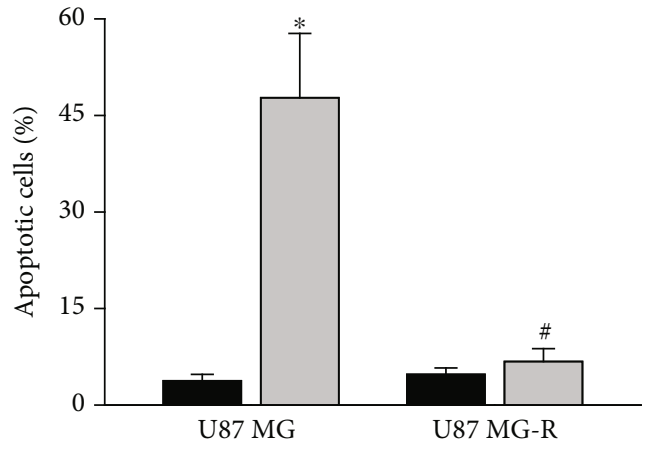

- Control

$\square$ TMZ

(d)

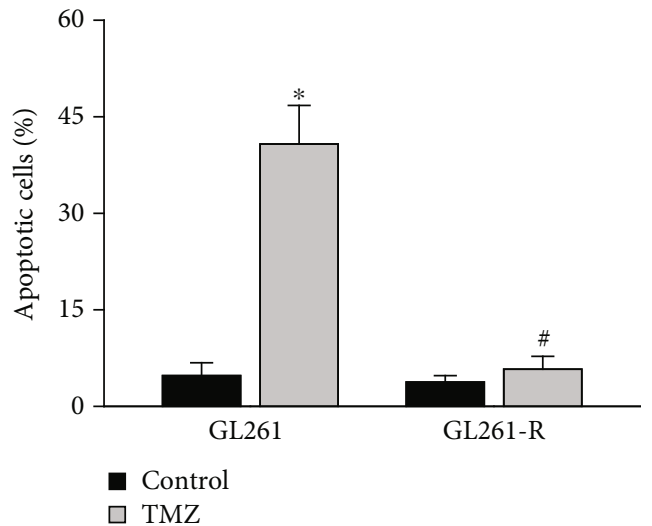

(f)

FIGURE 1: Selection and preparation of human drug-resistant glioblastoma cells. Human TMZ-tolerant U87 MG-R cells were selected from TMZ-sensitive U87 MG cells. (a) Morphologies of U87 MG and U87 MG-R cells are shown. Glioblastoma cells were exposed to TMZ at 25, 50,75 , and $100 \mu \mathrm{M}$ for $72 \mathrm{~h}$. (b) Cell survival was assayed using a trypan blue exclusion method. (c, d) A cellular ELISA kit and a flow cytometric method were used to quantify DNA fragmentation and apoptotic cells, respectively. Murine GL261 and GL261-R glioblastoma cells were exposed to TMZ at $100 \mu \mathrm{M}$. (e, f) DNA fragmentation and apoptotic cells were analyzed. Data are expressed as the mean \pm SD for $n=6 .{ }^{*} p<0.05$ vs. control and ${ }^{\#} p<0.05$ vs. U87 MG.

treatment with $\mathrm{CoCl}_{2}$ for $6 \mathrm{~h}$ reduced cell numbers (Figure 2(c)). After 12 and $24 \mathrm{~h}$, hypoxia induced more death of human TMZ-tolerant glioblastoma cells. Moreover, our survival analysis showed that treatment of human U87 MG-R cells with $100 \mu \mathrm{M} \mathrm{CoCl}_{2}$ for 6,12 , and $24 \mathrm{~h}$, respectively, diminished cell survival by $19 \%, 31 \%$, and $49 \%$ 


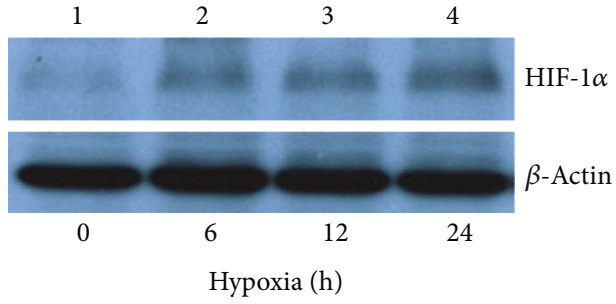

(a)

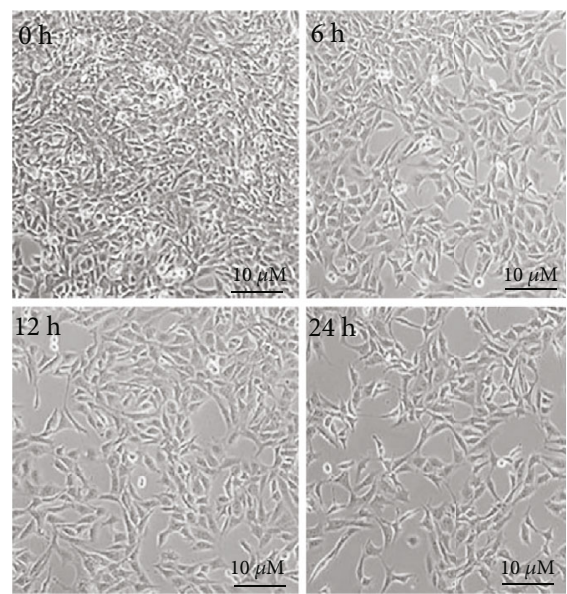

(c)

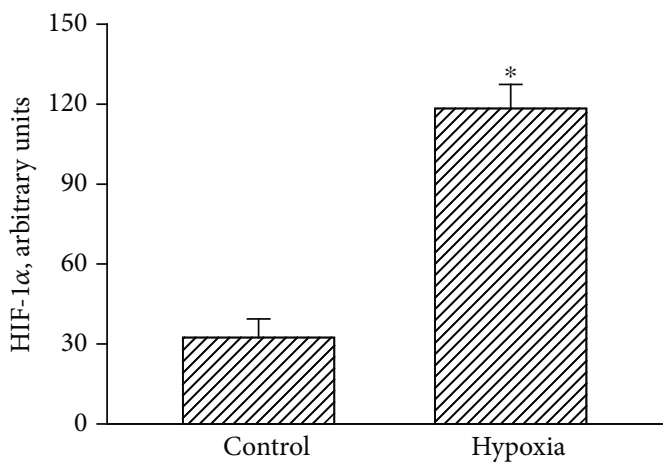

(e)

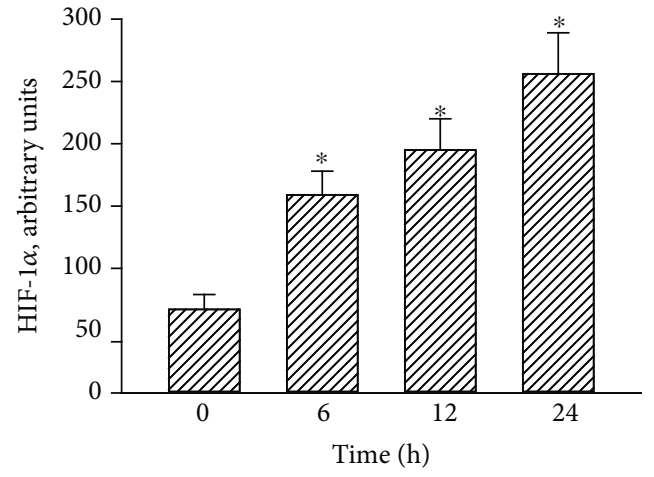

(b)

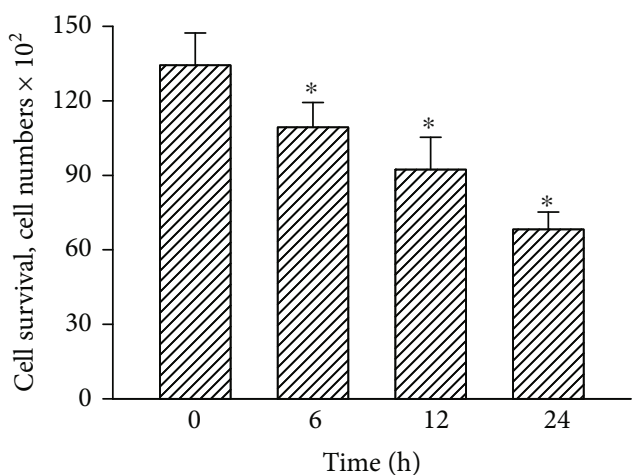

(d)

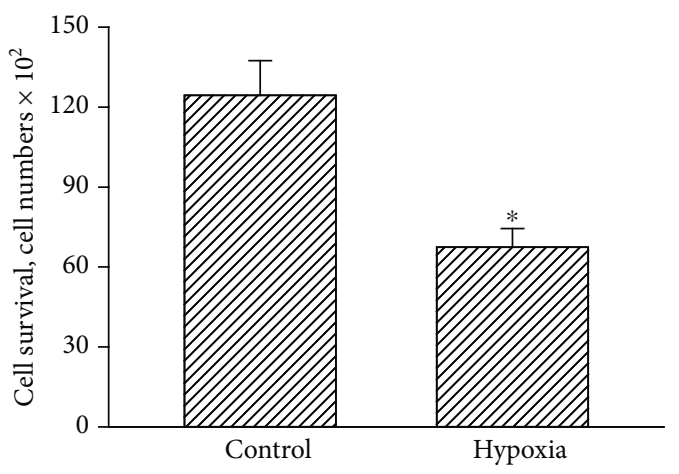

(f)

FIgURE 2: Effects of hypoxia induced by $\mathrm{CoCl}_{2}$ on levels of hypoxia-inducible factor- (HIF-) $1 \alpha$ and cell survival in human drug-resistant glioblastoma cells. Human drug-tolerant U87 MG-R cells were selected from TMZ-sensitive U87 MG cells. U87 MG-R cells were treated with hypoxia for 6,12 , and $24 \mathrm{~h}$. (a) Levels of HIF- $1 \alpha$ were immunodetected (top panel). $\beta$-Actin was analyzed as the internal control (bottom panel). (b) These protein bands were quantified and statistically analyzed. (c) Cell morphology was observed and photographed. (d) Cell survival was assayed with a trypan blue exclusion method. Mouse GL261-R glioblastoma cells were exposed to hypoxia for 24 h. (e, f) Levels of HIF- $1 \alpha$ and cell survival were analyzed. Data are expressed as the mean \pm SD for $n=6 .{ }^{*} p<0.05$ vs. control.

(Figure 2(d)). The HIF-1 $\alpha$ levels in mouse GL261-R glioblastoma cells increased 3.6-fold following treatment with $100 \mu \mathrm{M} \mathrm{CoCl} 2$ for $24 \mathrm{~h}$ (Figure 2(e)). Exposure of mouse GL261-R cells to $\mathrm{CoCl}_{2}$ led to a $46 \%$ reduction in cell survival (Figure 2(f)).
3.3. Hypoxia Induced by $\mathrm{CoCl}_{2}$ Triggered Mitochondrial Dysfunction, Proliferation Inhibition, and Cell Autophagy in Human and Mouse Drug-Resistant Glioblastoma Cells. Effects of the $\mathrm{CoCl}_{2}$-induced hypoxia insults to mitochondrial functions, cell proliferation, and cell autophagy were 


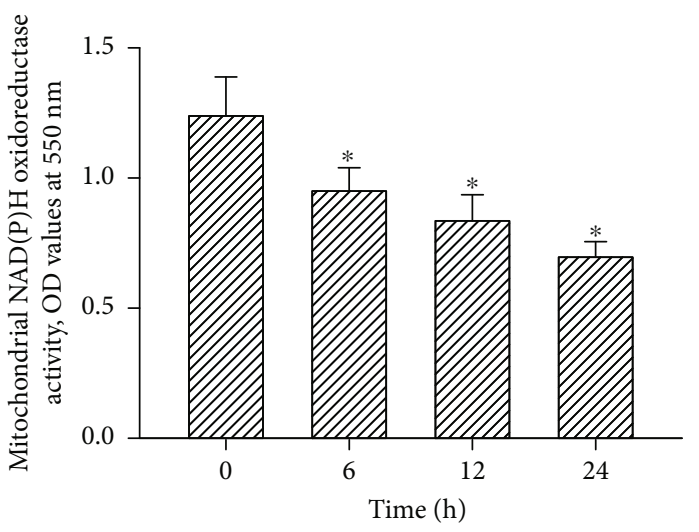

(a)

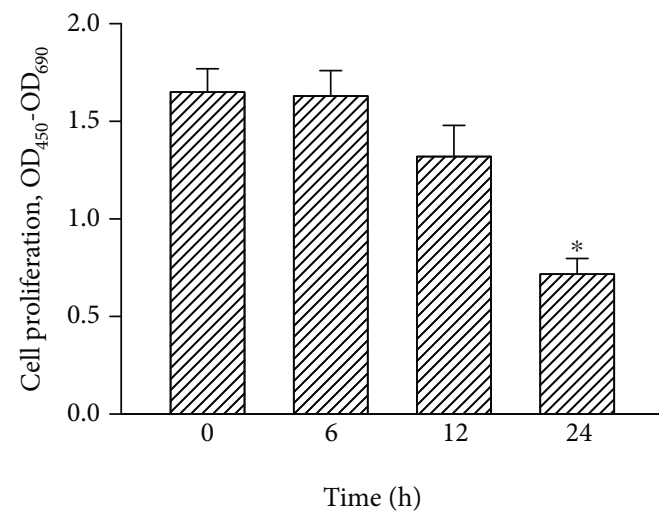

(c)

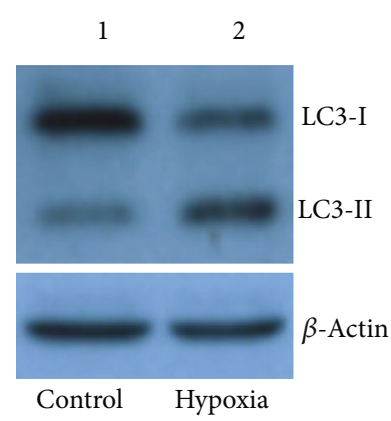

(e)

Control

Hypoxia

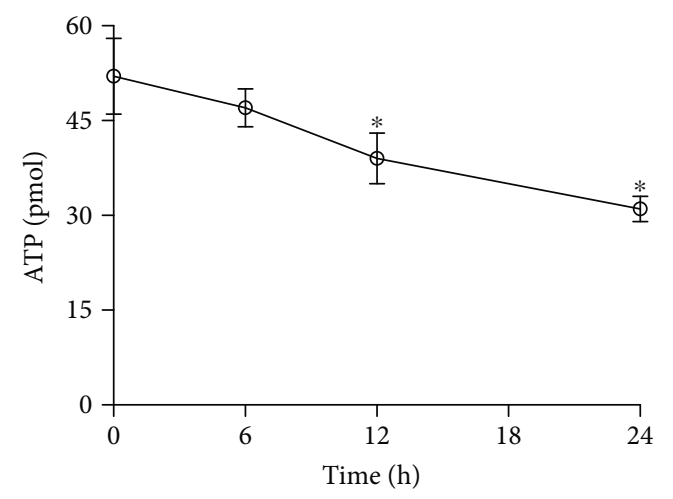

(b)
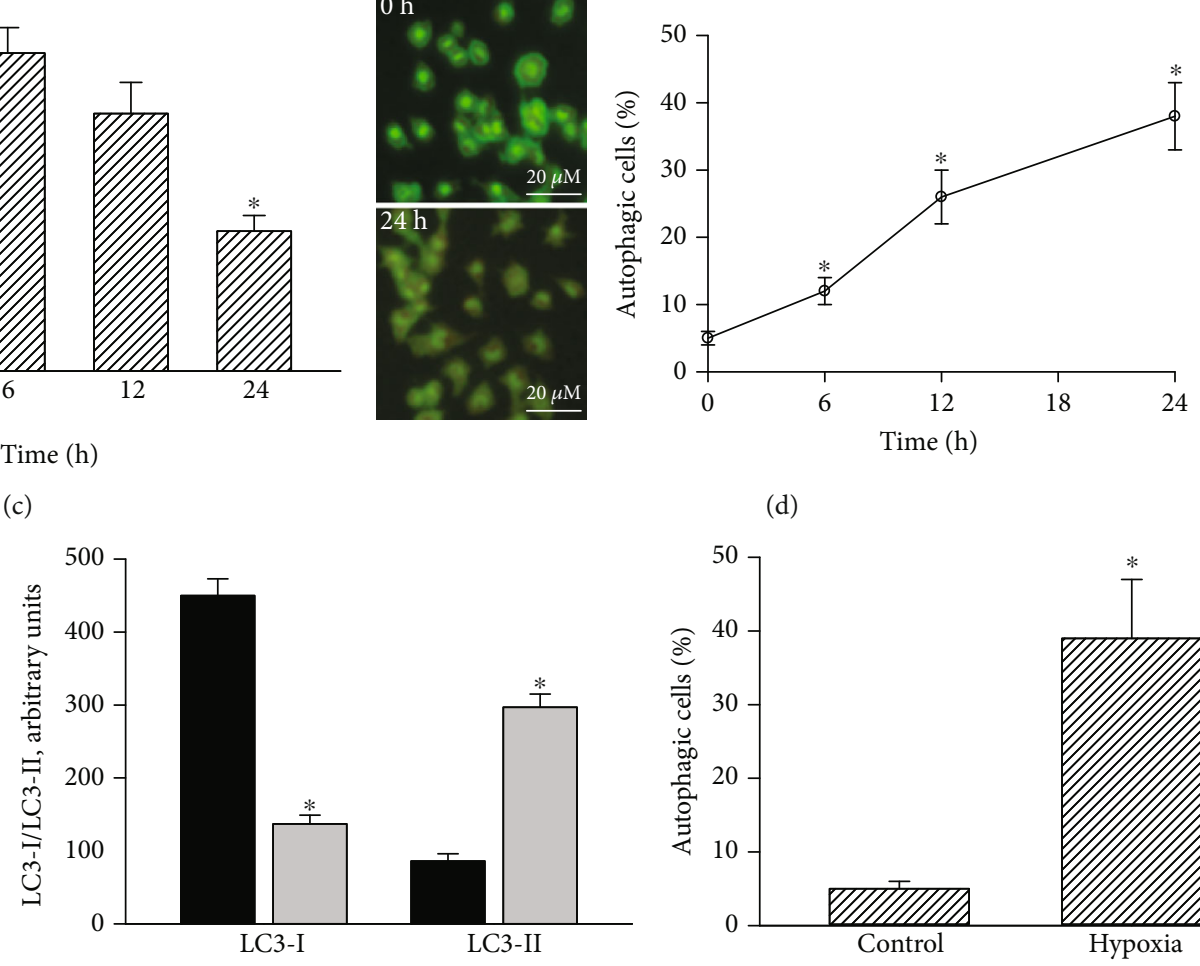

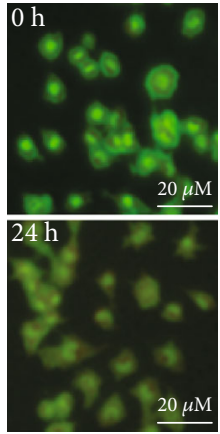

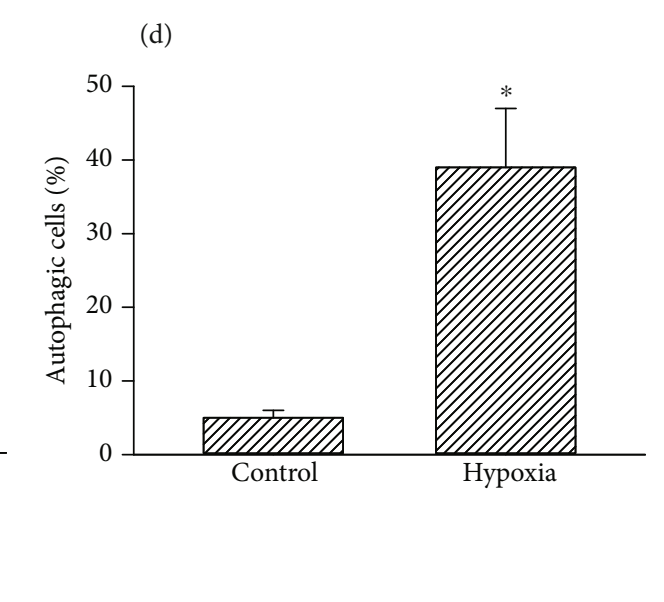

(d)

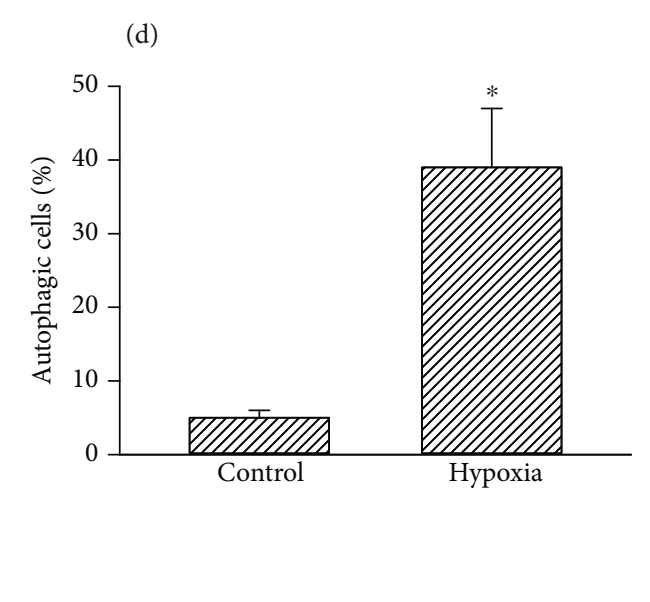

(g)

FIGURE 3: Effects of hypoxia induced by $\mathrm{CoCl}_{2}$ on mitochondrial NADH dehydrogenase activity, ATP levels, cell proliferation, cell autophagy, and levels of light chain (LC)3-I and LC3-2 in human drug-resistant glioblastoma cells. Human TMZ-tolerant U87 MG-R cells were selected from TMZ-sensitive U87 MG cells. U87 MG-R glioblastoma cells were treated with hypoxia for 6, 12, and 24 h. (a) Activity of mitochondrial $\mathrm{NADH}$ dehydrogenase was assayed using a colorimetric method. (b) Levels of ATP were measured using a bioluminescence assay. (c) Cell proliferation was measured by a thymidine incorporation assay. (d) Autophagic cells with acidic vesicular organelles were observed and photographed using a fluorescent microscope (left panel) and quantified with flow cytometry (right panel). (e) Levels of LC3-I and LC3-II were immunodetected (top panels). $\beta$-Actin was measured as the internal control (bottom panels). (f) These protein bands were quantified and statistically analyzed. Mouse GL261-R glioblastoma cells were exposed to hypoxia for 24h. (g) Autophagic cells were quantified. Data are expressed as the mean \pm SD for $n=6 .{ }^{*} p<0.05$ vs. control.

consecutively determined (Figure 3). Activities of mitochondrial $\mathrm{NAD}(\mathrm{P}) \mathrm{H}$ enzymes in U87 MG-R cells decreased by $23 \%, 32 \%$, and $44 \%$ following respective exposure to $\mathrm{CoCl}_{2}$ for 6,12 , and $24 \mathrm{~h}$ (Figure 3(a)). Subsequently, treatment with $\mathrm{CoCl}_{2}$ for 12 and $24 \mathrm{~h}$ led to respective $25 \%$ and $40 \%$ reduc- tions in cellular ATP levels (Figure 3(b)). Moreover, at $24 \mathrm{~h}$ after hypoxic administration, proliferation of human TMZresistant glioblastoma cells had dropped by $56 \%$ (Figure 3(c)).

Remarkably, exposure of human drug-tolerant glioblastoma cells to $\mathrm{CoCl}_{2}$ for $24 \mathrm{~h}$ induced the cells with acidic 


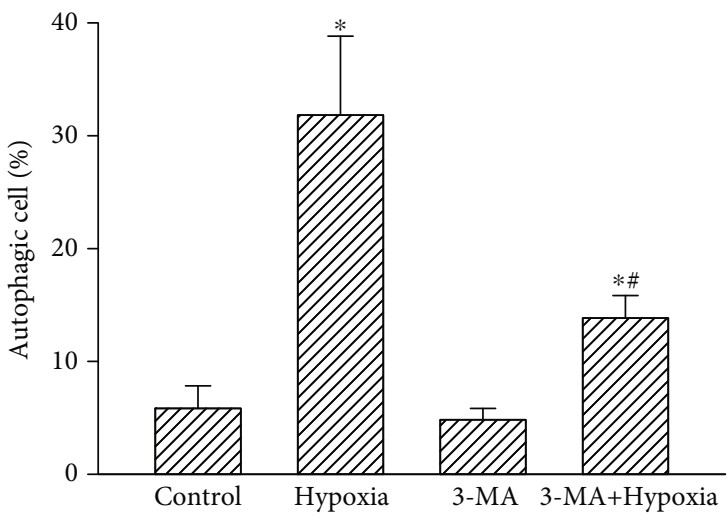

(a)

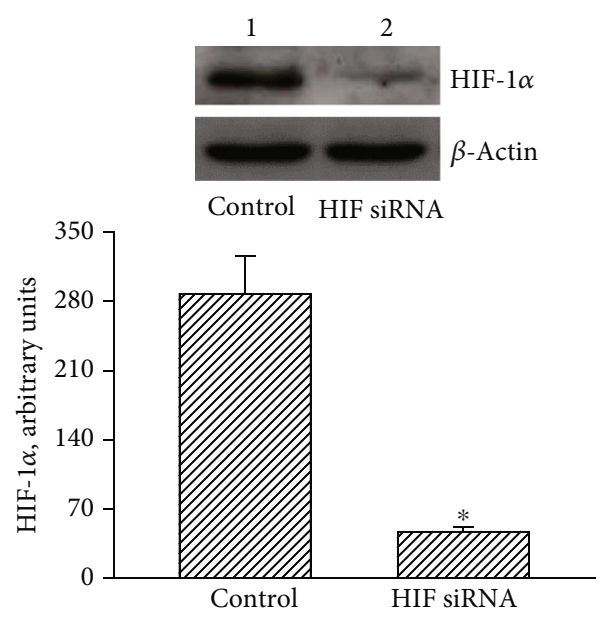

(c)

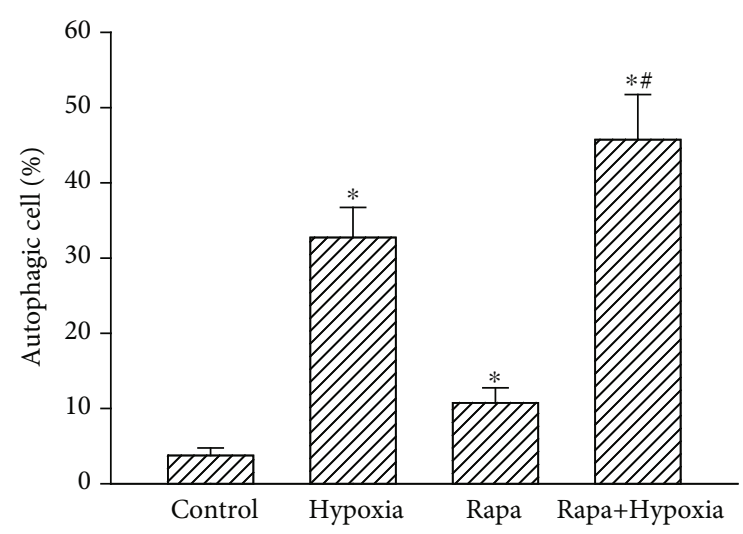

(b)

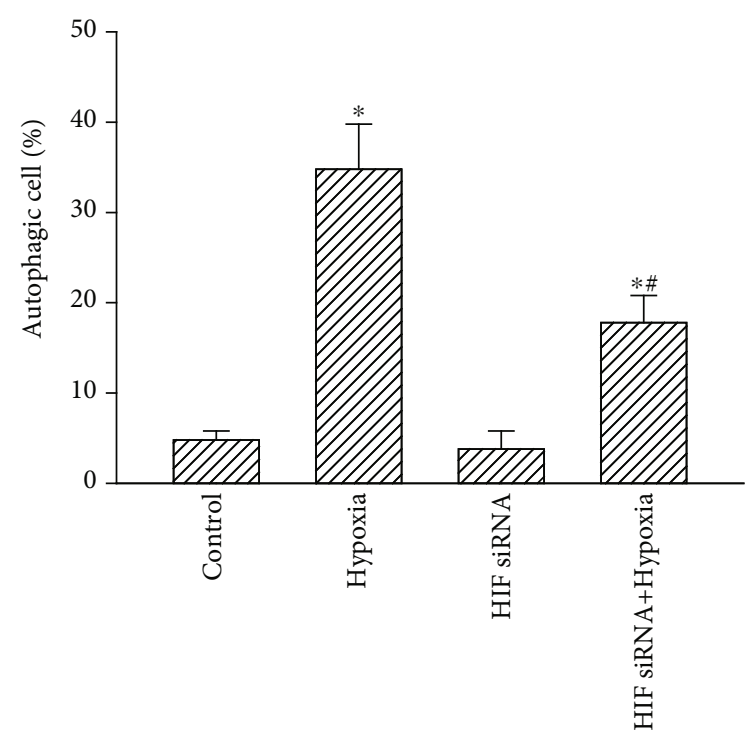

(d)

FIgURE 4: Effects of 3-methyladenine (3-MA), rapamycin (Rapa), and hypoxia-inducible factor- (HIF-) $1 \alpha$ knockdown on autophagy of human drug-resistant glioblastoma cells. Human temozolomide- (TMZ-) resistant U87 MG-R glioblastoma cells were selected from TMZsensitive U87 MG cells. $(\mathrm{a}, \mathrm{b})$ Human U87 MG-R glioblastoma cells were pretreated with 3-MA at $1 \mathrm{mM}$ or Rapa at $0.5 \mu \mathrm{M}$ for $1 \mathrm{~h}$ and then exposed to hypoxia for additional $24 \mathrm{~h}$. Control cells received DMSO only. A flow cytometric method was carried out to quantify autophagic cells. (c) Human U87 MG-R cells were treated with HIF-1 $\alpha$ small interfering (si) RNA (HIF siRNA) for 48 h. Scrambled siRNA was applied to control cells as the negative control (control). HIF- $1 \alpha$ was immunodetected, and $\beta$-actin was analyzed as the internal control. These protein bands were quantified and statistically analyzed. (d) Human U87 MG-R cells were pretreated with HIF-1 $\alpha$ siRNA and then exposed to hypoxia. Autophagic cells were quantified using flow cytometry. Data are expressed as the mean \pm SD for $n=$ $6 .{ }^{*} p<0.05$ vs. control and ${ }^{\#} p<0.05$ vs. U87 MG.

vesicles organelle (Figure 3(d), left panel). A flow cytometric examination revealed that exposure to $\mathrm{CoCl}_{2}$ for $6 \mathrm{~h}$ increased acidic vesicular organelles in human drug-tolerant glioblastoma cells by $12 \%$ (right panel). Following $\mathrm{CoCl}_{2}$ treatment for 12 and $24 \mathrm{~h}$, autophagic cells were, respectively, increased $26 \%$ and $38 \%$. An immunoblot image shows that LC3-I and -II in untreated U87 MG-R cells were detected (Figure 3(e), top panels, lane 1). Administration of $\mathrm{CoCl}_{2}$ for $24 \mathrm{~h}$ decreased levels of LC3-I but increased amounts of LC3-II (lane 2). $\beta$ Actin was immunodetected as the internal loading standard (bottom panel). Hypoxic treatment decreased of LC3-I by $69 \%$ but increased of LC3-II by $240 \%$ in TMZ-resistant glio- blastoma cells (Figure 3(f)). Meanwhile, the $\mathrm{CoCl}_{2}$-induced hypoxia caused $39 \%$ of mouse GL261-R cells to undergo autophagy (Figure 3(g)).

3.4. $\mathrm{CoCl}_{2}$ Induced Hypoxic Insults to Human Drug-Resistant

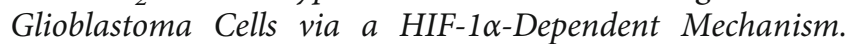
Loss- and gain-of-function strategies were conducted to confirm the effects of the $\mathrm{CoCl}_{2}$-induced hypoxia on autophagic insults to TMZ-tolerant glioblastoma cells (Figures 4(a) and 4(b)). Administration of $\mathrm{CoCl}_{2}$ induced autophagy of human drug-resistant U87 MG-R cells by 32\% (Figure 4(a)). In the control group, pretreatment with 3-MA alone did not trigger 
cell autophagy. However, administration of 3-MA attenuated hypoxia-induced autophagic insults to human U87 MG-R cells by $69 \%$ (Figure $4(\mathrm{a})$ ). In contrast, pretreatment of human drug-tolerant glioblastoma cells with rapamycin did not influence cell autophagy (Figure 4(b)). Nevertheless, pretreatment with rapamycin increased hypoxia-induced autophagic insults to U87 MG-R cells by $45 \%$.

At the same time, roles of $\mathrm{HIF}-1 \alpha$ in $\mathrm{CoCl}_{2}$-induced autophagy of human drug-resistant U87 MG-R glioblastoma cells were further investigated (Figures 4(c) and 4(d)). Application of HIF-1 $\alpha$ small interfering (si) RNA to human U87 MG-R cells for $48 \mathrm{~h}$ caused obvious attenuation of HIF- $1 \alpha$ levels compared to untreated cells (Figure 4(c), top panel). Protein bands were quantified using $\beta$-actin as the loading control, and the data were statistically analyzed. After application of HIF- $1 \alpha$ siRNA, levels of HIF- $1 \alpha$ in human U87 MG-R cells were reduced by $83 \%$ (Figure 4(c), bottom panel). The $\mathrm{CoCl}_{2}$-induced hypoxia triggered $35 \%$ of U87 MG-R cells undergoing autophagy (Figure 4(d)). Application of HIF- $1 \alpha$ siRNA to human TMZ-resistant glioblastoma cells did not trigger cell autophagy. In comparison, knocking down HIF-1 $\alpha$ translation concurrently suppressed $57 \%$ of hypoxia-induced autophagic insults to human U87 MG-R cells (Figure 4(d)).

3.5. The $\mathrm{CoCl}_{2}$-Induced Hypoxia Sequentially Decreased Levels of PI3K and Subsequent Phosphorylation of AKT and mTOR in Human Drug-Resistant Glioblastoma Cells. Molecular mechanisms of $\mathrm{CoCl}_{2}$-induced insults to human TMZ-tolerant glioblastoma cells were further investigated (Figure 5). In the control group, PI3K was immunodetected in human U87 MG-R glioblastoma cells (Figure 5(a), top panel, lane 1). In contrast, administration of $\mathrm{CoCl}_{2}$ to human glioblastoma cells obviously decreased levels of PI3K (lane 2). Intensities of these protein bands were measured using $\beta$-actin as a loading standard (bottom panel), and the data were statistically analyzed (Figure 5(b)). Exposure to hypoxia caused a $77 \%$ reduction in PI3K levels in human U87 MG-R cells (Figure 5(b)). Consecutively, AKT phosphorylation in U87 MG-R cells was alleviated following exposure to $\mathrm{CoCl}_{2} \mathrm{Com}-$ pared to the control group (Figure 5(c), top panel). AKT and $\beta$-actin were measured as internal controls (bottom two panels). The $\mathrm{CoCl}_{2}$-induced hypoxia diminished phosphorylation of $\mathrm{AKT}$ in human TMZ-resistant glioblastoma cells by $89 \%$ (Figure 5(d)). Consequently, hypoxia reduced mTOR phosphorylation in human U87 MG-R cells (Figure 5(e), top panel). mTOR and $\beta$-actin were measured as the internal controls (bottom two panels). Exposure of human drugtolerant glioblastoma cells to hypoxia led to $91 \%$ repression of mTOR phosphorylation (Figure 5(f)).

3.6. Hypoxia Induced by $\mathrm{CoCl}_{2}$ Triggered Autophagy and Subsequent Apoptosis of Human and Mouse Drug-Resistant Glioblastoma Cells. Treatment of human drug-resistant glioblastoma cells with $\mathrm{CoCl}_{2}$ enhanced the activity of caspase- 3 by 2.5-fold (Figure 6(a)). Pretreatment with 3-MA did change activation of caspase-3. Nonetheless, 3-MA lowered hypoxia-induced caspase- 3 activation by $62 \%$ (Figure $6(\mathrm{a})$ ). Sequentially, caspase-6 activity in human U87 MG-R glio- blastoma cells increased 2.5-fold (Figure 6(b)). Pretreatment with 3-MA alone did not affect caspase-6 activity but attenuated $\mathrm{CoCl}_{2}$-triggered activation of caspase- 6 by $52 \%$. Exposure to $\mathrm{CoCl}_{2}$ led to a 2.5-fold induction of DNA fragmentation in U87 MG-R cells (Figure 6(c)). In parallel, hypoxia triggered $29 \%$ of human U87 MG-R cells to undergo apoptosis (Figure 6(d)). Pretreatment with 3-MA did not affect the DNA integrity or cell apoptosis. In contrast, pretreatment of human TMZ-tolerant glioblastoma cells with 3-MA caused significant $76 \%$ and $72 \%$ depressions in hypoxia-induced DNA fragmentation and cell apoptosis, respectively (Figures 6(c) and 6(d)). In addition, administration of hypoxia augmented caspase- 3 activities by twofold in mouse GL261-R cells (Figure 6(e)). Subsequently, exposure of mouse drug-resistant GL261-R cells to $\mathrm{CoCl}_{2}$ caused a significant 2.3-fold stimulation of DNA fragmentation (Figure 6(f)). Accordingly, apoptotic insults to mouse drugresistant glioblastoma cells were induced by $31 \%$ after $\mathrm{CoCl}_{2}$ administration (Figure 6(g)).

3.7. Exposure to Hypoxia for $96 \mathrm{~h}$ Induced Apoptotic Insults to Human Drug-Resistant Glioblastoma Cells without Affecting Human Normal Astrocytes. Treatment of human U87 MG-R cells to $\mathrm{CoCl}_{2}$ for $96 \mathrm{~h}$ decreased cell viability by 92\% (Figure 7(a)). In addition, exposure to $\mathrm{CoCl}_{2}$ for $96 \mathrm{~h}$ caused $16 \%$ and $88 \%$ of human drug-resistant glioblastoma cells undergoing autophagy and apoptosis, respectively (Figures 7(b) and 7(c)). The safety of $\mathrm{CoCl}_{2}$ to human normal HA-h astrocytes was then evaluated (Figures 7(d)-7(f)). Exposure of HA-h cells to $100 \mu \mathrm{M} \mathrm{CoCl}_{2}$ for $96 \mathrm{~h}$ did not influence cell viability (Figure $7(\mathrm{~d})$ ). In contrast, treatment with $\mathrm{CoCl}_{2}$ for $96 \mathrm{~h}$ led to a slight $21 \%$ induction of HA-h cells undergoing autophagy but did not trigger apoptotic insults (Figures 7(e) and $7(\mathrm{f}))$.

\section{Discussion}

Administration of $\mathrm{CoCl}_{2}$ can induce hypoxic conditions and consequent autophagic apoptosis of drug-resistant glioblastoma cells. In this study, we demonstrated that exposure to $\mathrm{CoCl}_{2}$ could trigger hypoxic stress to human and murine TMZ-resistant glioblastoma cells. In parallel, hypoxic conditions disrupted mitochondrial ATP synthesis and induced death of cells of these two drug-resistant glioblastoma cell lines. In addition, hypoxia suppressed proliferation of human TMZ-tolerant glioblastoma cells. GBM is the commonest and most aggressive brain tumor [1]. Inopportunely, GBM patients have very poor prognoses because most patients eventually have become drug-resistant and recurrent [3]. To the present, TMZ is routinely used as the first-line drug for treatment of GBM patients [2]. The malignance of glioblastomas can be elucidated because following surgery, residual glioblastoma cells can rapidly proliferate, migrate, and invade to the other sites for development of new brain tumors. Hypoxia is able to suppress proliferation and viability of drug-sensitive glioblastoma cells [25]. In the present study, we further identified the beneficial actions of the $\mathrm{CoCl}_{2}$-induced hypoxic conditions to suppress proliferation and survival of TMZ-resistant glioblastoma cells. As to the 


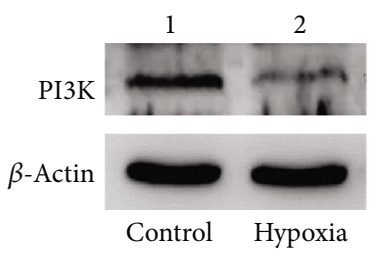

(a)

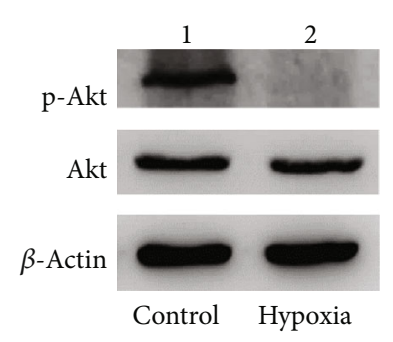

(c)

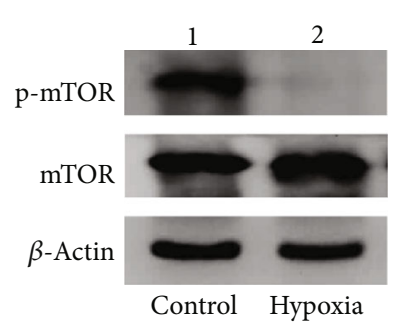

(e)

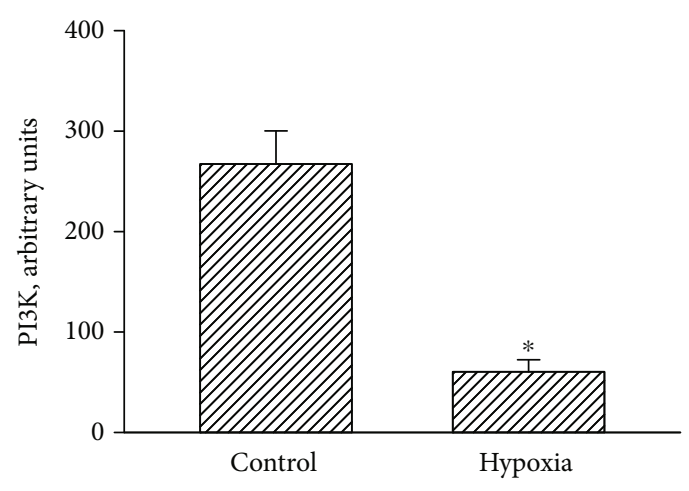

(b)

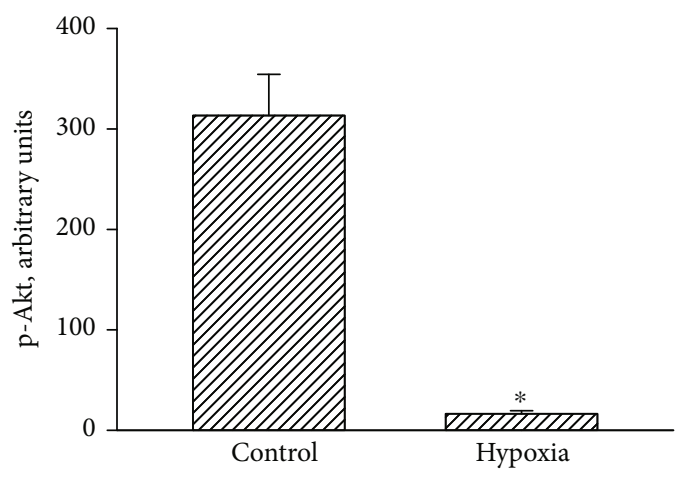

(d)

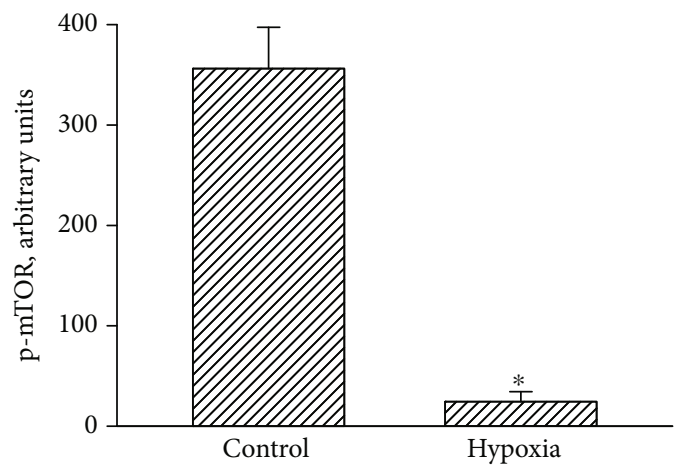

$(\mathrm{f})$

FIGURE 5: Signal-transducing mechanisms involved in hypoxia-induced autophagy of human drug-resistant glioblastoma cells. Human TMZtolerant U87 MG-R cells were selected from TMZ-sensitive U87 MG cells. Human U87 MG-R cells were treated with hypoxia for 24 h. (a, c, e) Levels of phosphoinositide 3-kinase (PI3K), phosphorylated- (p-) AKT, and p-mammalian target of rapamycin (mTOR) were immunodetected (top panels). $\beta$-Actin, AKT, and mTOR were analyzed as the internal controls for detection of PI3K, $\mathrm{p}$-AKT, and pmTOR, respectively (bottom panels). (b, d, f) These immunorelated protein bands were quantified and statistically analyzed. Data are expressed as the mean $\pm \mathrm{SD}$ for $n=6 .{ }^{*} p<0.05$ vs. control.

mechanisms, administration of hypoxic stress meaningfully induced autophagy and subsequent apoptosis of human and murine drug-resistant glioblastoma cells. In response to malnutrition, cells can temporarily survive by activating a process of self-degradation and catabolism, called autophagy [17]. Autophagic cells will subsequently either survive or proceed to necrosis or apoptosis $[17,18]$. Furthermore, autophagy was also shown to be involved in the prevention of certain diseases, including tumors [26]. The drug-resistant glioblastoma cells highly defend against apoptosis. Recently, we demonstrated advantages of a longer period of hypoxia induced by honokiol, a multifunctional antitumor drug, on the killing of human neuroblastoma cells and glioblastoma cells via an autophagic apoptosis pathway [23-25]. Recently, autophagic cell death has attracted researchers as a potential method for cancer therapy. In this study, we provide serial evidence to show the benefits of $\mathrm{CoCl}_{2}$-induced hypoxia of killing drug-resistant glioblastoma cells through activating an autophagic and subsequent apoptotic mechanism. As a result, longer hypoxia induced by certain agents such as 


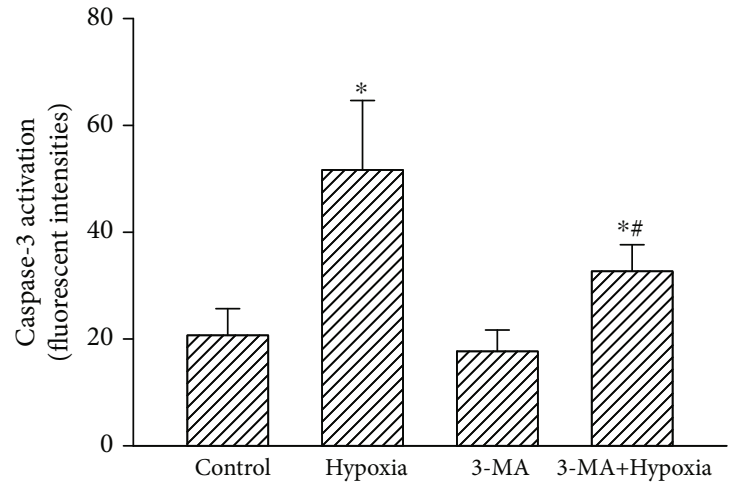

(a)

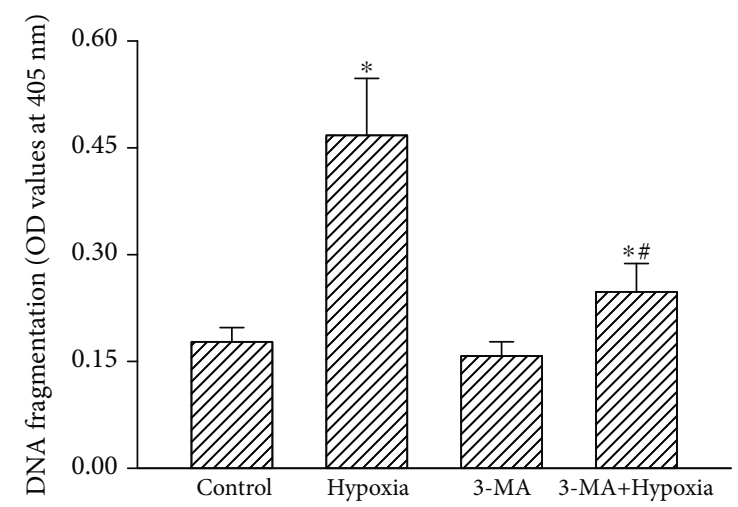

(c)

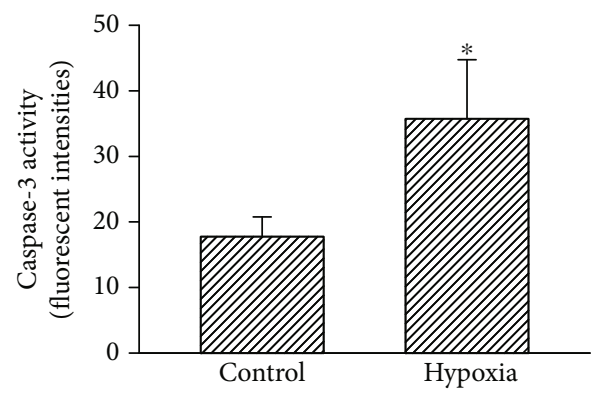

(e)

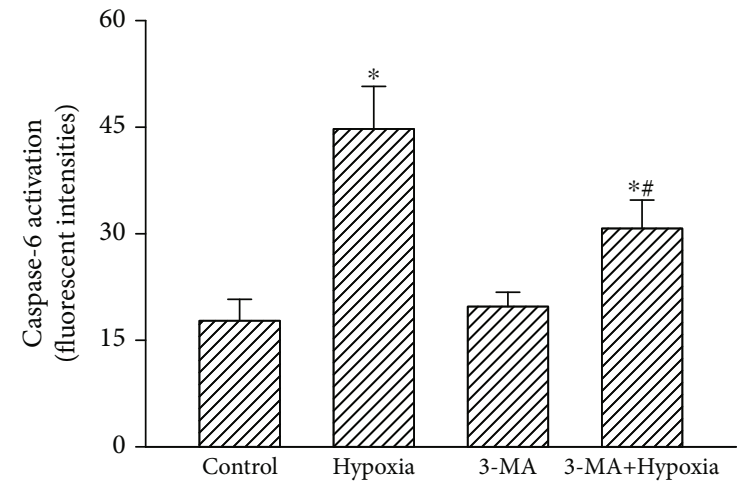

(b)

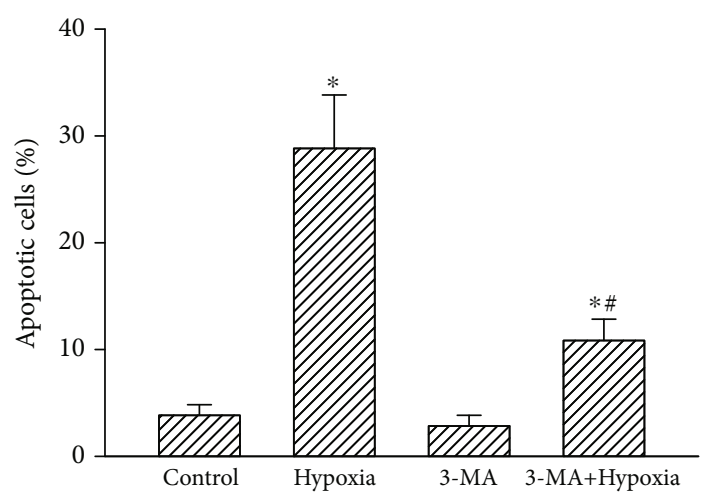

(d)

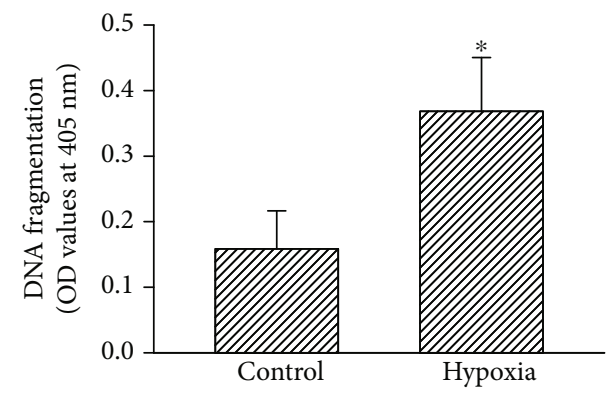

(f)

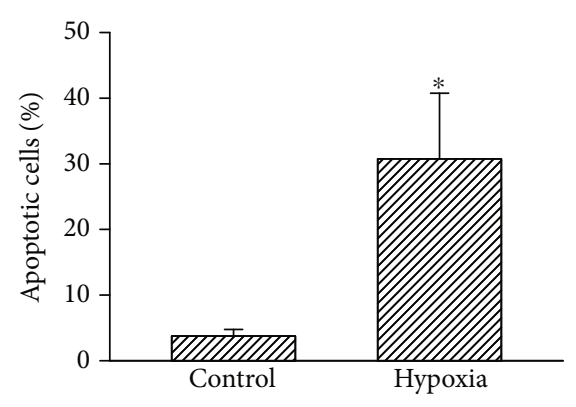

(g)

FIGURE 6: Effects of 3-MA on hypoxia-induced cascade activation of caspases-3 and -6, DNA fragmentation, and cell apoptosis in human drug-resistant glioblastoma cells. Human U87 MG-R glioblastoma cells were pretreated with $1 \mathrm{mM} 3-\mathrm{MA}$ for $1 \mathrm{~h}$. Then, the cells were treated with hypoxia for $24 \mathrm{~h}$. ( $\mathrm{a}, \mathrm{b}$ ) Cascade activation of caspase- 3 and caspase- 6 were examined with a fluorometric substrate assay. (c, d) DNA fragmentation and apoptotic cells were analyzed. Mouse GL261-R glioblastoma cells were exposed to hypoxia for 24h. (e-g) Caspase-3 activity, DNA fragmentation, and apoptotic cells were assayed. Data are expressed as the mean \pm SD for $n=6 .{ }^{*} p<0.05$ vs. control and ${ }^{\#} p<0.05$ vs. U87 MG. 


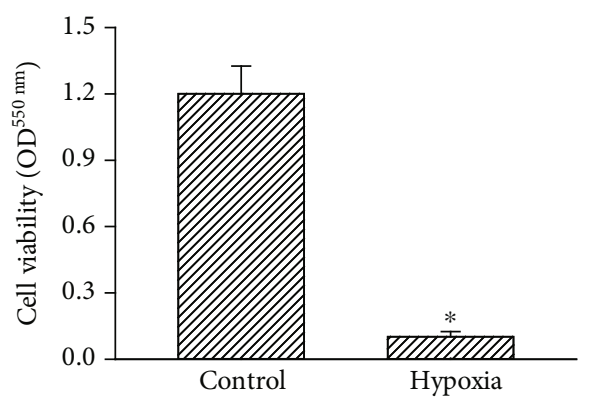

(a)

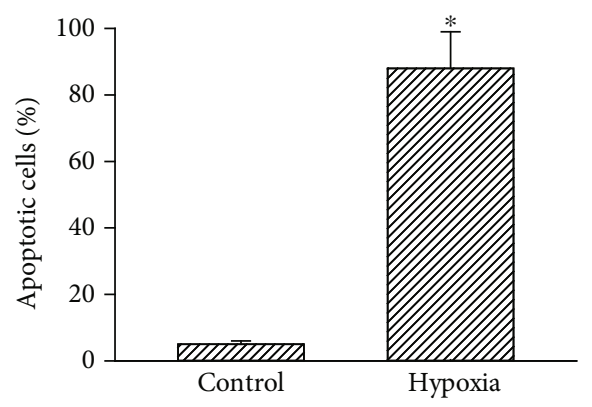

(c)

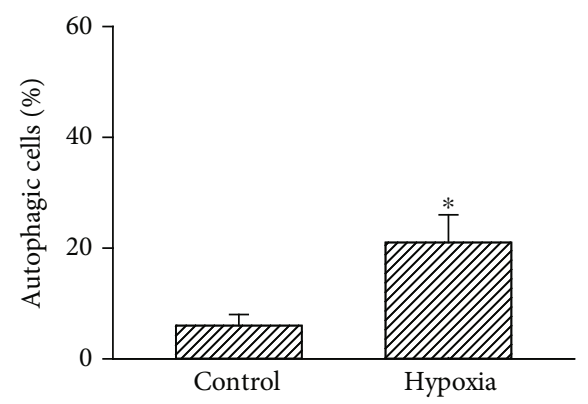

(e)

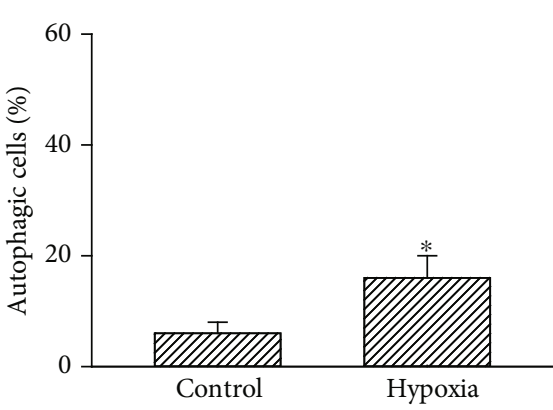

(b)

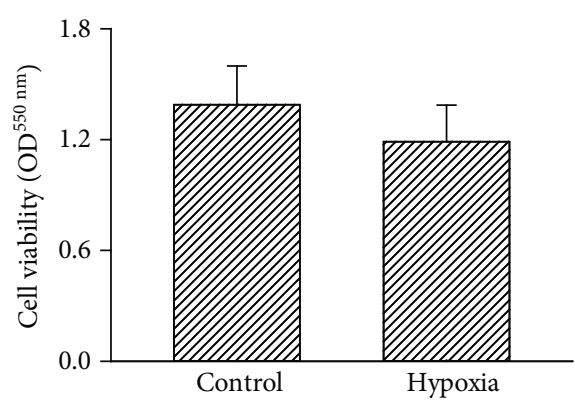

(d)

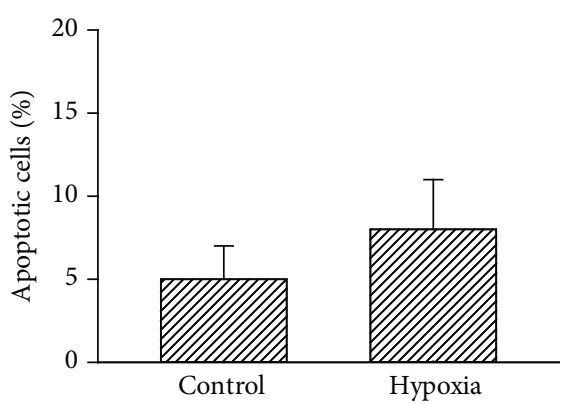

(f)

FiguRE 7: Effects of $\mathrm{CoCl}_{2}$ treatment for $96 \mathrm{~h}$ on viability, autophagy, and apoptosis of human drug-resistant glioblastoma cells and normal astrocytes. (a-c) Human temozolomide- (TMZ-) resistant U87 MG-R glioblastoma cells and (d-f) human HA-h astrocytes were exposed to $\mathrm{CoCl}_{2}$ for 96 h. (a, d) Cell viability was assayed using a colorimetric method. (b, e) Autophagic and (c, f) apoptotic cells were quantified using flow cytometry. Each value represents the mean \pm SD for $n=3$. The symbol ${ }^{*}$ indicates that a value significantly $(p<0.05)$ differed from the respective control group.

$\mathrm{CoCl}_{2}$ or honokiol may be clinically applied as a de novo strategy for treating chemoresistance in malignant and recurrent glioblastomas via an autophagic apoptosis pathway.

Administration of $\mathrm{CoCl}_{2}$ led to hypoxic stress and consequently induced insults to human and murine TMZ-resistant glioblastoma cells. Drug-resistant glioblastoma cells used in this study were prepared according to a continuous selection protocol described in our previous study [37]. Compared to chemosensitive human U87 MZ and mouse GL261 cells, these two TMZ-resistant U87 MZ-R and GL261-R cell lines have similar morphologies. Nevertheless, administration of TMZ induced apoptotic insults to human and mouse TMZsensitive glioblastoma cells but did not affect chemoresistant cells. Fascinatingly, exposure to $\mathrm{CoCl}_{2}$ time-dependently raises levels of HIF- $1 \alpha$ in drug-resistant glioblastoma cells. In the hypoxic microenvironment, HIF- $1 / 2 \alpha$, two transcriptional factors, can be massively induced to regulate certain gene expressions in response to oxygen deficiency-induced stress [16]. $\mathrm{CoCl}_{2}$ can chelate $\mathrm{Fe}^{2+}$ ions in hemoglobin to decrease the oxygen supply to cells [38]. Additionally, administration of $\mathrm{CoCl}_{2}$ raises levels of cellular HIF- $1 \alpha$ by inhibiting the activity of prolyl-4-hydroxylase, a HIF- $1 \alpha$-specific proteinase [39]. Thus, $\mathrm{CoCl}_{2}$ can elevate levels of HIF- $1 \alpha$ in human and mouse TMZ-resistant glioblastoma cells and induce intracellular hypoxic stress. At the same time, the $\mathrm{CoCl}_{2}$-induced hypoxia diminished proliferation and survival of drug-resistant glioblastoma cells. In tumorigenesis, hypoxia can stimulate the proliferation of tumor cells via a HIF- $1 \alpha$-dependent transcriptional mechanism [40]. Nonetheless, Dai et al. reported that in a $\mathrm{CoCl}_{2}$-induced hypoxic microenvironment, proliferation and viability of PC-2 cells were lessened, and the cells underwent apoptosis [41]. Our previous studies also demonstrated the oppressive effects $\mathrm{CoCl}_{2}$ on the proliferation and survival of drug-sensitive 
glioblastoma cells [25]. In parallel, enzyme activity of mitochondrial $\mathrm{NAD}(\mathrm{P}) \mathrm{H}$ oxidoreductase and levels of cellular ATP in human TMZ-resistant glioblastoma cells were repressed following exposure to hypoxia. Thus, the $\mathrm{CoCl}_{2}$ induced hypoxia suppressed proliferation and survival of drug-resistant glioblastoma cells via lowering mitochondrial ATP synthesis. However, the reasons explain the relation between ATP reductions on suppression of cell proliferation in hypoxia-treated drug-resistant glioblastoma cells need to be further investigated.

Hypoxia induced by $\mathrm{CoCl}_{2}$ can trigger autophagy of human and murine drug-resistant glioblastoma cells via a HIF-1 $\alpha$-dependent pathway. Our flow cytometric analysis of acidic vesicular organelles in human and mouse drugtolerant glioblastoma cells revealed that administration of $\mathrm{CoCl}_{2}$ time-dependently induced autophagic insults. Simultaneously, the ratio of LC3-II over LC3-I significantly increased after exposure to $\mathrm{CoCl}_{2}$. When the cells are undergoing autophagy, acidic vesicular organelles were formed [23, 42]. At the same time, the ratio of LC3-II over LC3-I was enhanced. In this study, we further used gain- and loss-offunction strategies to confirm the hypoxia-induced autophagy of TMZ-resistant glioblastoma cells. As usual, 3-MA and rapamycin were applied as a respective inhibitor and an inducer of cell autophagy [43]. After administration of 3-MA and rapamycin to chemoresistant glioblastoma cells, hypoxia-induced autophagic insults were, respectively, attenuated and enhanced. Thus, multiple lines of evidence showed the action of the $\mathrm{CoCl}_{2}$-induced hypoxia in inducing autophagy of drug-resistant glioblastoma cells, thereby inducing autophagic insults to TMZ-resistant glioblastoma cells. More interestingly, knocking down HIF- $1 \alpha$ concurrently lowered $\mathrm{CoCl}_{2}$-induced autophagic insults to human TMZ-resistant glioblastoma cells. HIF- $1 \alpha$ can induce cell autophagy via inducing BNIP3 and LC3 expressions [22]. In addition, a previous study reported that prolonged hypoxia induced mitochondrial autophagy via activation of a HIF- $1 \alpha / \mathrm{BINP} 3 /-$ Beclin-1/Atg5 mechanism [44]. In the present study, exposure to $\mathrm{CoCl}_{2}$ led to consequent mitochondrial dysfunction. As a result, one possible mechanism explaining $\mathrm{CoCl}_{2}$ induced autophagy of human drug-resistant glioblastoma cells is via triggering HIF- $1 \alpha$-dependent mitochondrial autophagy. Being a potential target for cancer therapy, autophagy has recently attracted attention of oncologic physicians and researchers [45]. Chemoresistance and recurrence are two critical factors driving malignance and poor prognoses of GBM patients [6]. In this study, we provide in vitro evidence to demonstrate the potential effects of prolonged hypoxia induced by $\mathrm{CoCl}_{2}$ for treating $\mathrm{GBM}$ by inducing autophagic insults to drug-resistant glioblastomas.

Hypoxia induced by $\mathrm{CoCl}_{2}$ led to autophagy of human drug-resistant glioblastoma cells through targeting the PI3K-AKT-mTOR pathway. After exposure to $\mathrm{CoCl}_{2}$, levels of PI3K in human TMZ-resistant glioblastoma cells were significantly diminished. In tumorigenesis, PI3K is genetically overexpressed or mutated in the brain, breasts, prostate, stomach, colon, and endometrium [46]. So, targeting PI3K was investigated as a new strategy for treating various types of tumors such as breast cancer [47]. AKT is a downstream

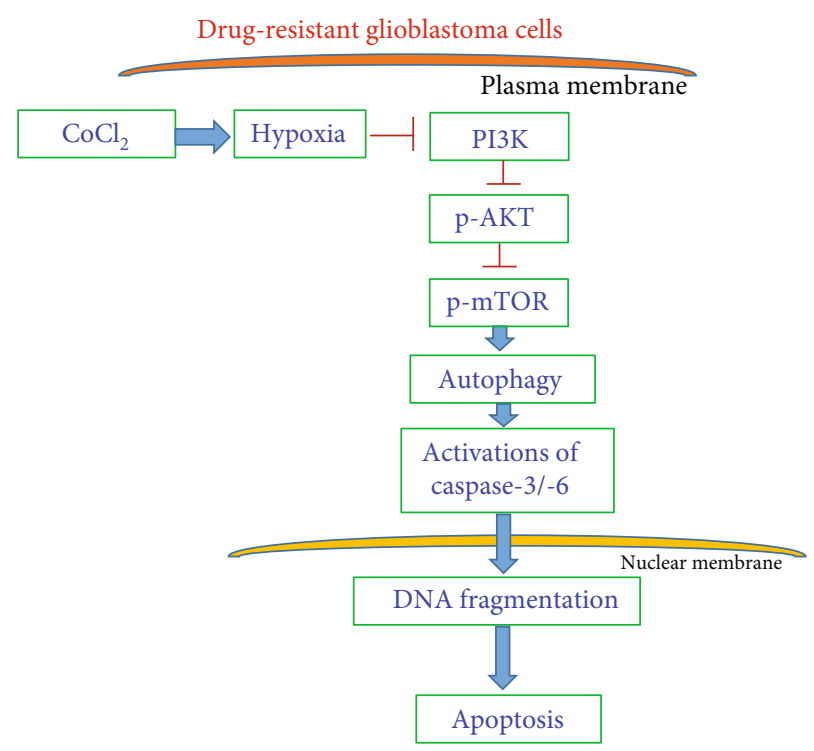

Figure 8: Proposed signal-transducing pathways of hypoxiainduced autophagy and subsequently apoptotic killing of human drug-resistant glioblastoma cells. Treatment of human TMZresistant glioblastoma cells with $\mathrm{CoCl}_{2}$ induces hypoxic insults by suppressing phosphoinositide 3-kinase- (PI3K-) involved signaltransducing phosphorylations of AKT and mammalian target of rapamycin (mTOR). Consequently, long-period administration of $\mathrm{CoCl}_{2}$ induced cascade activation of caspases- 3 and -6, DNA breakage, and apoptotic insults to human drug-resistant glioblastoma cells.

target of PI3K. Our present data reveal that treatment with $\mathrm{CoCl}_{2}$ decreased levels of AKT in human drug-tolerant glioblastoma cells. Hence, the hypoxia-induced downregulation of AKT was due to suppression of PI3K production. Inhibition of the PI3K/AKT pathway is recognized as a new weapon for fighting cancer incidence [46]. Our present data prove the suppressive effects of $\mathrm{CoCl}_{2}$ against the proliferation of human TMZ-resistant glioblastoma cells. Thus, the hypoxia-induced blockage of the PI3K-AKT pathway may be beneficial for inhibiting the growth of chemoresistant glioblastomas. mTOR, a serine/threonine protein kinase, plays a crucial role in the balance between catabolism and anabolism [48]. Phosphorylation of mTOR, activated by the PI3K-AKT pathway, can drive cellular catabolism and depress cell autophagy [49]. In parallel with an interruption of the PI3K/AKT pathway, $\mathrm{CoCl}_{2}$ weakened phosphorylation of mTOR in human TMZ-resistant glioblastoma cells. Hence, one possible mechanism explaining the $\mathrm{CoCl}_{2}$-induced reduction in levels of phosphorylated mTOR in TMZresistant glioblastomas is due to disruption of the PI3KAKT pathway. In addition to HIF- $1 \alpha, \mathrm{HIF}-2 \alpha$ is another factor that can be upregulated by hypoxia [16]. Under hypoxic conditions, the proteasome-dependent stability of HIF$1 / 2 \alpha$ is involved in regulation of tumor-induced angiogenesis and metastasis via the PI3K/AKT pathway [50]. In aggressive neuroblastomas, Mohlin et al. reported that suppression of HIF- $2 \alpha$ by targeting PI3K/mTORC1 can improve therapeutic efficacy [51]. This study demonstrated that knocking down HIF-1 $\alpha$ simultaneously attenuated hypoxia-induced 
cell autophagy. Therefore, the $\mathrm{CoCl}_{2}$-induced hypoxia can trigger autophagic insults to drug-resistant glioblastoma cells via targeting the PI3K-AKT-mTOR pathway.

Hypoxia induced by $\mathrm{CoCl}_{2}$ triggered autophagic apoptosis of human and murine drug-resistant glioblastoma cells. Prolonged exposure to $\mathrm{CoCl}_{2}$ of human and murine TMZresistant glioblastoma cells induced cascade activation of caspases-3 and -6, DNA fragmentation, and cell cycle arrest at the sub- $\mathrm{G}_{1}$ phase. Caspase activation, DNA fragmented damage, and cell cycle arrest are characteristic features indicating that cells are undergoing apoptosis $[52,53]$. Interestingly, pretreatment of human TMZ-resistant glioblastoma cells with 3-MA reduced hypoxia-induced autophagy. At the same time, $\mathrm{CoCl}_{2}$-induced cascade activation of caspases- 3 and -6 , DNA breakage, and apoptosis in human TMZtolerant glioblastoma cells were significantly lowered following pretreatment with 3-MA. Autophagic cells will survive or proceed to die $[17,18]$. Our present data showed that prolonged administration of $\mathrm{CoCl}_{2}$ can induce autophagic insults to TMZ-resistant glioblastoma cells, resulting in cell death via an apoptotic mechanism. Autophagic cell death is recognized as a separate form of cell death from cell apoptosis and necrosis [54]. Nonetheless, our present study showed that $\mathrm{CoCl}_{2}$ can trigger autophagic apoptosis of human TMZtolerant glioblastoma cells. Specific induction of apoptosis of tumor cells can be applied as an anticancer mechanism for cancer therapy [53]. However, GBM is a very aggressive tumor because it is usually hard to induce apoptosis in glioblastoma cells by chemotherapeutic drugs [55]. Therefore, hypoxia-induced autophagic apoptosis has the potential to serve as an alternative strategy for therapy of brain tumors.

\section{Conclusions}

In this study, we successfully selected human and mouse drug-resistant glioblastoma cells as our experimental models. Exposure of human and mouse TMZ-resistant glioblastoma cells to $\mathrm{CoCl}_{2}$ increased HIF- $1 \alpha$ levels and induced hypoxic stress and insults (Figure 8). Subsequently, prolonged hypoxia induced by $\mathrm{CoCl}_{2}$ led to mitochondrial dysfunction. Interestingly, administration of hypoxia elevated proportions of drug-resistant glioblastoma cells with acidic organelles and the ratio of cellular LC3-II over LC3-I. Loss- and gain-offunction strategies were used to further demonstrate that pretreatment with 3-MA and rapamycin, respectively, attenuated and enhanced consequent $\mathrm{CoCl}_{2}$-induced cell autophagy. Importantly, knocking down HIF- $1 \alpha$ translation using RNAi concurrently diminished $\mathrm{CoCl}_{2}$-induced cell autophagy. Thus, these manifold lines of evidence showed that prolonged hypoxia induced by $\mathrm{CoCl}_{2}$ could trigger hypoxic insults to human and mouse TMZ-resistant glioblastoma cells via a HIF- $1 \alpha$-dependent mechanism. As to the mechanisms, administration of $\mathrm{CoCl}_{2}$ decreased signal-transducing activation of PI3K and AKT (Figure 8). Successively, levels of phosphorylated mTOR in human drug-resistant glioblastoma cells were reduced by $\mathrm{CoCl}_{2}$. Fascinatingly, prolonged administration of hypoxia sequentially induced cascade activation of caspases-3 and -6, DNA fragmentation, and apoptotic insults in TMZ-tolerant glioblastoma cells (Figure 8). Using 3-MA to suppress $\mathrm{CoCl}_{2}$-induced autophagy simultaneously defended against apoptotic damage. Therefore, this study showed that prolonged hypoxia induced by $\mathrm{CoCl}_{2}$ can induce autophagic apoptosis of drug-resistant glioblastoma cells via suppression of the PI3K-AKT-mTOR pathway (Figure 8). To the present, chemoresistance and recurrence are the most serious issues and challenges for therapy of GBM patients. $\mathrm{CoCl}_{2}$-induced hypoxia and subsequent autophagic apoptosis may be a de novo strategy for treating glioblastomas. We are carrying out a translational study to further confirm our in vitro findings.

\section{Data Availability}

All data generated or analyzed during this study are included in this article.

\section{Conflicts of Interest}

The authors declare that there is no conflict of interest.

\section{Authors' Contributions}

Y.-W. Lee and Y.-G. Cherng equally contribute to this scientific work.

\section{Acknowledgments}

This study was supported by grants from Taipei Medical University Hospital (108TMU-TMUH-06), Wan Fang Hospital (110-wf-swf-05), the Ministry of Science and Technology (MOST 109-2320-B-038-066), and TMU Research Center of Cancer Translational Medicine from The Featured Areas Research Center Program within the framework of the Higher Education Sprout Project by the Ministry of Education (MOE), Taipei, Taiwan. The authors express their gratitude to Ms. Yi-Ling Lin for her technical support and data collection for the experiments.

\section{Supplementary Materials}

Figure S1: effects of $\mathrm{CoCl}_{2}$ on levels of vimentin in human drug-resistant glioblastoma cells. Human TMZ-tolerant U87 MG-R cells were selected from TMZ-sensitive U87 MG cells. U87 MG-R glioblastoma cells were treated with hypoxia for 6,12 , and $24 \mathrm{~h}$. (a) Levels of vimentin were immunodetected. $\beta$-Actin was analyzed as the internal control. (b) These immunorelated protein bands were quantified and statistically analyzed. Data are expressed as the mean \pm SD for $n=3$. (Supplementary materials)

\section{References}

[1] C. M. Jackson, J. Choi, and M. Lim, "Mechanisms of immunotherapy resistance: lessons from glioblastoma," Nature Immunology, vol. 20, no. 9, pp. 1100-1109, 2019.

[2] F. Sharifzad, S. Ghavami, J. Verdi et al., "Glioblastoma cancer stem cell biology: potential theranostic targets," Drug Resistance Updates, vol. 42, pp. 35-45, 2019. 
[3] D. Fabian, M. Guillermo Prieto Eibl, I. Alnahhas et al., "Treatment of glioblastoma (GBM) with the addition of tumortreating fields (TTF): a review," Cancers, vol. 11, no. 2, p. 174, 2019.

[4] W. Tomaszewski, L. Sanchez-Perez, T. F. Gajewski, and J. H. Sampson, "Brain tumor microenvironment and host state: implications for immunotherapy," Clinical Cancer Research, vol. 25, no. 14, pp. 4202-4210, 2019.

[5] J. Adhikaree, J. Moreno-Vicente, A. P. Kaur, A. M. Jackson, and P. M. Patel, "Resistance mechanisms and barriers to successful immunotherapy for treating glioblastoma," Cell, vol. 9, no. 2, p. 263, 2020.

[6] A. Kirstein, T. E. Schmid, and S. E. Combs, "The role of miRNA for the treatment of MGMT unmethylated glioblastoma multiforme," Cancers, vol. 12, article E1099, 2020.

[7] B. W. Wong, E. Marsch, L. Treps, M. Baes, and P. Carmeliet, "Endothelial cell metabolism in health and disease: impact of hypoxia," The EMBO Journal, vol. 36, no. 15, pp. 2187-2203, 2017.

[8] C. Nyakas, B. Buwalda, and P. G. Luiten, "Hypoxia and brain development," Progress in Neurobiology, vol. 49, no. 1, pp. 151,1996

[9] J. W. Lee, J. Ko, C. Ju, and H. K. Eltzschig, "Hypoxia signaling in human diseases and therapeutic targets," Experimental \& Molecular Medicine, vol. 51, no. 12, pp. 1-13, 2019.

[10] N. N. Nalivaeva, A. J. Turner, and I. A. Zhuravin, "Role of prenatal hypoxia in brain development, cognitive functions, and neurodegeneration," Frontiers in Neuroscience, vol. 12, p. 825, 2018.

[11] R. Kunze and H. H. Marti, “Angioneurins- key regulators of blood-brain barrier integrity during hypoxic and ischemic brain injury," Progress in Neurobiology, vol. 178, p. 101611, 2019.

[12] F. Irani, J. M. Barbone, J. Beausoleil, and L. Gerald, "Is asthma associated with cognitive impairments? A meta-analytic review.," Journal of Clinical and Experimental Neuropsychology, vol. 39, no. 10, pp. 965-978, 2017.

[13] S. Jawhari, M. H. Ratinaud, and M. Verdier, "Glioblastoma, hypoxia and autophagy: a survival-prone 'ménage-à-trois'," Cell Death \& Disease, vol. 7, no. 10, article e2434, 2016.

[14] S. Nicolas, S. Abdellatef, M. A. Haddad, I. Fakhoury, and M. El-Sibai, "Hypoxia and EGF stimulation regulate VEGF expression in human glioblastoma multiforme (GBM) cells by differential regulation of the PI3K/Rho-GTPase and MAPK pathways," Cell, vol. 8, no. 11, p. 1397, 2019.

[15] G. Gabriely, M. A. Wheeler, M. C. Takenaka, and F. J. Quintana, "Role of AHR and HIF- $1 \alpha$ in glioblastoma metabolism," Trends in Endocrinology and Metabolism, vol. 28, no. 6, pp. 428-436, 2017.

[16] L. Holmquist-Mengelbier, E. Fredlund, T. Löfstedt et al., "Recruitment of HIF- $1 \alpha$ and HIF- $2 \alpha$ to common target genes is differentially regulated in neuroblastoma: HIF- $2 \alpha$ promotes an aggressive phenotype," Cancer Cell, vol. 10, no. 5, pp. 413423, 2006.

[17] D. Glick, S. Barth, and K. F. Macleod, “Autophagy: cellular and molecular mechanisms," The Journal of Pathology, vol. 221, no. 1, pp. 3-12, 2010.

[18] A. K. Yadav, P. K. Yadav, G. R. Chaudhary et al., "Autophagy in hypoxic ovary," Cellular and Molecular Life Sciences, vol. 76, no. 17, pp. 3311-3322, 2019.
[19] D. G. Hardie, "Sensing of energy and nutrients by AMPactivated protein kinase," The American Journal of Clinical Nutrition, vol. 93, no. 4, pp. 891S-896S, 2011.

[20] F. Chiacchiera and C. Simone, "Inhibition of p38alpha unveils an AMPK-FoxO3A axis linking autophagy to cancer-specific metabolism," Autophagy, vol. 5, no. 7, pp. 1030-1033, 2009.

[21] J. Pouyssegur, F. Dayan, and N. M. Mazure, "Hypoxia signalling in cancer and approaches to enforce tumour regression," Nature, vol. 441, no. 7092, pp. 437-443, 2006.

[22] G. Bellot, R. Garcia-Medina, P. Gounon et al., "Hypoxiainduced autophagy is mediated through hypoxia-inducible factor induction of BNIP3 and BNIP3L via their BH3 domains," Molecular and Cellular Biology, vol. 29, no. 10, pp. 2570-2581, 2009.

[23] P. S. Yeh, W. Wang, Y. A. Chang, C. J. Lin, J. J. Wang, and R. M. Chen, "Honokiol induces autophagy of neuroblastoma cells through activating the PI3K/Akt/mTOR and endoplasmic reticular stress/ERK1/2 signaling pathways and suppressing cell migration," Cancer Letters, vol. 370 , no. 1, pp. 66-77, 2016.

[24] M. C. Lin, Y. W. Lin, Y. Y. Tseng, Y. W. Lee, J. T. Chen, and R. M. Chen, "Honokiol induces autophagy and successive apoptotic insults to neuroblastomas via a p53-dependent mechanism," The American Journal of Chinese Medicine, vol. 47, pp. 859-912, 2019.

[25] B. C. Cheng, J. T. Chen, S. T. Yang, C. C. Chio, S. H. Liu, and R. M. Chen, "Cobalt chloride treatment induces autophagic apoptosis in human glioma cells via a p53-dependent pathway," International Journal of Oncology, vol. 50, no. 3, pp. 964-974, 2017.

[26] K. R. Parzych and D. J. Klionsky, “An overview of autophagy: morphology, mechanism, and regulation," Antioxidants \& Redox Signaling, vol. 20, no. 3, pp. 460-473, 2014.

[27] P. S. Yeh, J. T. Chen, Y. G. Cherng, S. T. Yang, Y. T. Tai, and R. M. Chen, "Methylpiperidinopyrazole attenuates estrogeninduced mitochondrial energy production and subsequent osteoblast maturation via an estrogen receptor alpha-dependent mechanism," Molecules, vol. 25, no. 12, p. 2876, 2020.

[28] M. H. Ho, M. H. Liao, Y. L. Lin, C. H. Lai, P. I. Lin, and R. M. Chen, "Improving effects of chitosan nanofiber scaffolds on osteoblast proliferation and maturation," International Journal of Nanomedicine, vol. 9, pp. 4293-4304, 2014.

[29] C. J. Lin, Y. A. Chang, Y. L. Lin, C. C. Chio, and R. M. Chen, "Preclinical effects of honokiol on treating glioblastoma multiforme via G1 phase arrest and cell apoptosis," Phytomedicine, vol. 23, no. 5, pp. 517-527, 2016.

[30] R. M. Chen, C. H. Wu, H. C. Chang et al., "Propofol suppresses macrophage functions through modulating mitochondrial membrane potential and cellular adenosine triphosphate levels," Anesthesiology, vol. 98, no. 5, pp. 1178-1185, 2003.

[31] C. C. Chio, L. Wei, T. G. Chen et al., "Neuron-derived orphan receptor 1 transduces survival signals in neuronal cells in response to hypoxia-induced apoptotic insults," Journal of Neurosurgery, vol. 124, no. 6, pp. 1654-1664, 2016.

[32] J. W. Lin, J. T. Chen, C. Y. Hong et al., "Honokiol traverses the blood-brain barrier and induces apoptosis of neuroblastoma cells via an intrinsic Bax-mitochondrion-cytochrome ccaspase protease pathway," Neuro-Oncology, vol. 14, no. 3, pp. 302-314, 2012.

[33] C. C. Chio, J. W. Lin, H. A. Cheng et al., "MicroRNA-210 targets antiapoptotic Bcl-2 expression and mediates hypoxia- 
induced apoptosis of neuroblastoma cells," Archives of Toxicology, vol. 87, pp. 458-468, 2013.

[34] C. J. Lin, T. L. Chen, Y. Y. Tseng et al., "Honokiol induces autophagic cell death in malignant glioma through reactive oxygen species-mediated regulation of the p53/PI3K/Akt/mTOR signaling pathway," Toxicology and Applied Pharmacology, vol. 304, pp. 59-69, 2016.

[35] C. C. Chio, Y. T. Tai, M. Mohanraj, S. H. Liu, S. T. Yang, and R. M. Chen, "Honokiol improves temozolomide-induced apoptotic insults to malignant glioma cells via an intrinsic mitochondria-dependent pathway," Phytomedicine, vol. 49, pp. 41-51, 2018.

[36] D. P. Sun, Y. W. Lee, J. T. Chen, Y. W. Lin, and R. M. Chen, "The bradykinin-BDKRB1 axis regulates aquaporin 4 gene expression and consequential migration and invasion of malignant glioblastoma cells via a $\mathrm{Ca}^{2+}$-MEK1-ERK1/2-NF$\kappa \mathrm{B}$ mechanism," Cancers, vol. 12, no. 3, p. 667, 2020.

[37] C. C. Chio, K. Y. Chen, C. K. Chang et al., "Improved effects of honokiol on temozolomide-induced autophagy and apoptosis of drug-sensitive and -tolerant glioma cells," BMC Cancer, vol. 18, no. 1, p. 379, 2018.

[38] M. A. Goldberg and T. J. Schneider, "Similarities between the oxygen-sensing mechanisms regulating the expression of vascular endothelial growth factor and erythropoietin," The Journal of Biological Chemistry, vol. 269, no. 6, pp. 4355-4359, 1994.

[39] W. G. Kaelin Jr. and P. J. Ratcliffe, "Oxygen sensing by metazoans: the central role of the HIF hydroxylase pathway," Molecular Cell, vol. 30, no. 4, pp. 393-402, 2008.

[40] M. E. Hubbi and G. L. Semenza, "Regulation of cell proliferation by hypoxia-inducible factors," American Journal of Physiology. Cell Physiology, vol. 309, no. 12, pp. C775C782, 2015.

[41] Z. J. Dai, J. Gao, X. B. Ma et al., "Up-regulation of hypoxia inducible factor- $1 \alpha$ by cobalt chloride correlates with proliferation and apoptosis in PC-2 cells," Journal of Experimental \& Clinical Cancer Research, vol. 31, no. 1, p. 28, 2012.

[42] H. Knævelsrud, S. R. Carlsson, and A. Simonsen, "SNX18 tubulates recycling endosomes for autophagosome biogenesis," Autophagy, vol. 9, no. 10, pp. 1639-1641, 2013.

[43] S. Ceccariglia, A. Cargnoni, A. R. Silini, and O. Parolini, "Autophagy: a potential key contributor to the therapeutic action of mesenchymal stem cells," Autophagy, vol. 16, no. 1, pp. 28-37, 2020.

[44] H. Zhang, M. Bosch-Marce, L. A. Shimoda et al., "Mitochondrial autophagy is an HIF-1-dependent adaptive metabolic response to hypoxia," The Journal of Biological Chemistry, vol. 283, no. 16, pp. 10892-10903, 2008.

[45] F. Cuomo, L. Altucci, and G. Cobellis, "Autophagy function and dysfunction: potential drugs as anti-cancer therapy," Cancers, vol. 11, no. 10, p. 1465, 2019.

[46] F. M. Elmenier, D. S. Lasheen, and K. A. M. Abouzid, "Phosphatidylinositol 3 kinase (PI3K) inhibitors as new weapon to combat cancer," European Journal of Medicinal Chemistry, vol. 183, p. 111718, 2019.

[47] B. Verret, J. Cortes, T. Bachelot, F. Andre, and M. Arnedos, "Efficacy of PI3K inhibitors in advanced breast cancer," Annals of Oncology, vol. 30, Supplement 10, pp. x12-x20, 2019.

[48] A. S. Dossou and A. Basu, "The emerging roles of mTORC1 in macromanaging autophagy," Cancers, vol. 11, no. 10, p. 1422, 2019.
[49] D. Heras-Sandoval, J. M. Pérez-Rojas, J. Hernández-Damián, and J. Pedraza-Chaverri, "The role of PI3K/AKT/mTOR pathway in the modulation of autophagy and the clearance of protein aggregates in neurodegeneration," Cellular Signalling, vol. 26, no. 12, pp. 2694-2701, 2014.

[50] S. Mohlin, A. Hamidian, K. von Stedingk et al., "PI3KmTORC2 but not PI3K-mTORC1 regulates transcription of HIF2A/EPAS1 and vascularization in neuroblastoma," Cancer Research, vol. 75, no. 21, pp. 4617-4628, 2015.

[51] S. Joshi, A. R. Singh, M. Zulcic, and D. L. Durden, "A macrophage-dominant PI3K isoform controls hypoxiainduced HIF $1 \alpha$ and HIF $2 \alpha$ stability and tumor growth, angiogenesis, and metastasis," Molecular Cancer Research, vol. 12, no. 10, pp. 1520-1531, 2014, Epub 2014 Aug 7.

[52] R. M. Chen, Y. L. Lin, and C. W. Chou, "GATA-3 transduces survival signals in osteoblasts through upregulation of bcl- $\mathrm{x}_{\mathrm{L}}$ gene expression," Journal of Bone and Mineral Research, vol. 25, no. 10, pp. 2193-2204, 2010.

[53] G. Pistritto, D. Trisciuoglio, C. Ceci, A. Garufi, and G. D'Orazi, "Apoptosis as anticancer mechanism: function and dysfunction of its modulators and targeted therapeutic strategies," Aging, vol. 8, no. 4, pp. 603-619, 2016.

[54] A. Thorburn, "Apoptosis and autophagy: regulatory connections between two supposedly different processes," Apoptosis, vol. 13, no. 1, pp. 1-9, 2008.

[55] A. Escamilla-Ramírez, R. A. Castillo-Rodríguez, S. ZavalaVega et al., "Autophagy as a potential therapy for malignant glioma," Pharmaceuticals, vol. 13, no. 7, p. 156, 2020. 